\title{
Renal Sympathetic Denervation Attenuates \\ Congestive Heart Failure in Angiotensin II-Dependent Hypertension: Studies with Ren-2 Transgenic Hypertensive Rats with Aortocaval Fistula
}

\author{
Zuzana Honetschlagerováa Olga Gawrys ${ }^{a, b}$ Šárka Jíchováa \\ Petra Škaroupkováa Soňa Kikerlováa Zdeňka Vaňourkováa Zuzana Huskováa \\ Vojtěch Melenovskýb Elzbieta Kompanowska-Jezierskac Janusz Sadowskic

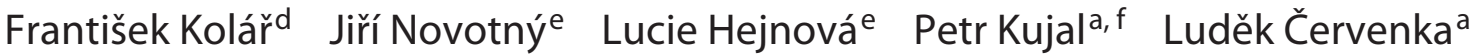 \\ ${ }^{a}$ Center for Experimental Medicine, Institute for Clinical and Experimental Medicine, Prague, Czech Republic; \\ ${ }^{b}$ Department of Cardiology, Institute for Clinical and Experimental Medicine, Prague, Czech Republic; \\ 'Department of Renal and Body Fluid Physiology, Mossakowski Medical Research Centre, Polish Academy of \\ Science, Warsaw, Poland; ${ }^{d}$ Department of Developmental Cardiology, Institute of Physiology of the Czech

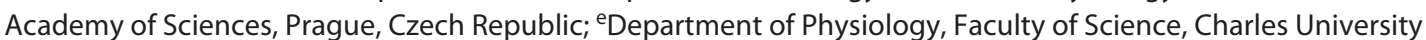 \\ in Prague, Prague, Czech Republic; f Department of Pathology, 3rd Faculty of Medicine, Charles University, \\ Prague, Czech Republic
}

\section{Keywords}

Congestive heart failure $\cdot$ Hypertension - Aortocaval fistula · Renal blood flow $\cdot$ Renal vascular reactivity · Angiotensin II · Renal denervation

\begin{abstract}
Objective: We examined if renal denervation (RDN) attenuates the progression of aortocaval fistula (ACF)-induced heart failure or improves renal hemodynamics in Ren-2 transgenic rats (TGR), a model of angiotensin II (ANG II)-dependent hypertension. Methods: Bilateral RDN was performed 1 week after creation of ACF. The animals studied were ACF TGR and sham-operated controls, and both groups were subjected to RDN or sham denervation. In separate
\end{abstract}

karger@karger.com www.karger.com/kbr

Karger $\frac{1}{\%}$

GOPEN ACCESS
(C) 2021 The Author(s)

Published by S. Karger AG, Basel

This article is licensed under the Creative Commons AttributionNonCommercial-NoDerivatives 4.0 International License (CC BYNC-ND) (http://www.karger.com/Services/OpenAccessLicense) Usage and distribution for commercial purposes as well as any distribution of modified material requires written permission. groups, renal artery blood flow (RBF) responses were determined to intrarenal ANG II ( 2 and $8 \mathrm{ng}$ ), norepinephrine (NE) (20 and $40 \mathrm{ng}$ ) and acetylcholine (Ach) (10 and $40 \mathrm{ng}) 3$ weeks after ACF creation. Results: In nondenervated ACF TGR, the final survival rate was 10 versus $50 \%$ in RDN rats. RBF was significantly lower in ACF TGR than in sham-operated TGR $\left(6.2 \pm 0.3\right.$ vs. $\left.9.7 \pm 0.5 \mathrm{~mL} \mathrm{~min}^{-1} \mathrm{~g}^{-1}, p<0.05\right)$, the levels unaffected by RDN. Both doses of ANG II decreased RBF more in ACF TGR than in sham-operated TGR $(-19 \pm 3$ vs. $-9 \pm 2 \%$ and $-47 \pm 3$ vs. $-22 \pm 2 \%, p<0.05$ in both cases). RDN did not alter RBF responses to the lower dose, but increased it to the higher dose of ANG II in sham-operated as well as in ACF TGR. NE comparably decreased RBF in ACF TGR and shamoperated TGR, and RDN increased RBF responsiveness. Intrarenal Ach increased RBF significantly more in ACF TGR than 
in sham-operated TGR ( $29 \pm 3$ vs. $17 \pm 3 \%, p<0.05)$, the changes unaffected by RDN. ACF creation induced marked bilateral cardiac hypertrophy and lung congestion, both attenuated by RDN. In sham-operated but not in ACF TGR, RDN significantly decreased mean arterial pressure. Conclusion: The results show that RDN significantly improved survival rate in ACF TGR; however, this beneficial effect was not associated with improvement of reduced RBF or with attenuation of exaggerated renal vascular responsiveness to ANG II.

(C) 2021 The Author(s)

Published by S. Karger AG, Basel

\section{Introduction}

Over the past decades, a substantial progress has been made in the treatment of myocardial infarction (MI), largely due to introduction into clinical practice of the early coronary reperfusion by primary percutaneous intervention. While the mortality of patients with acute MI and acute complications of cardiovascular diseases has decreased, the number of patients who develop congestive heart failure $(\mathrm{CHF})$ has been increasing progressively $[1,2]$. CHF has become a major public health problem, affecting currently $>6.5$ million people in the USA [3] and 9.2 million people in the EU [2]; the yearly increase in the number of new CHF patients is estimated at $>1.1$ million $[2,3]$. In spite of an array of therapeutic approaches available and recent pharmacological advances, such as combined application of neprilysin inhibitor and angiotensin II (ANG II) receptor blocker (sacubitril/valsartan) [2, 4], the prognosis of patients is still gloomy, especially with CHF accompanied by impairment of renal hemodynamics; indeed, it is worse than in most types of common cancers [2-5]. Even though it has been proposed that renal dysfunction and hypertension are 2 most important independent risk factors for the progression of CHF, current pharmacological regimes usually fail to prevent renal dysfunction in CHF patients, particularly those who were hypertensive before the onset of CHF [6]. Therefore, new therapeutic measures targeting renal dysfunction in $\mathrm{CHF}$ are needed.

In this context, it should be emphasized that reduced renal blood flow (RBF) is a common finding in patients with $\mathrm{CHF}$ and it is detected in the very early stage, when cardiac function is only minimally impaired and the glomerular filtration rate (GFR) remains in the physiological range [6-8]. Since adequate perfusion of the kidneys is a prerequisite for normal renal function [9], the decrease in $\mathrm{RBF}$ is acknowledged as the first sign of the development of renal dysfunction in CHF $[6-8,10]$. Even though $>6$ decades ago renal abnormalities were detected already in mild heart disease, long before the onset of overt CHF [10], and later studies demonstrated that alterations of renal hemodynamics preceded the development of $\mathrm{CHF}$ [11], most clinicians conceive the kidney as a victim of chronic hypoperfusion and chronic maladaptive responses to neurohormonal activation. However, considering the ample clinical and experimental research, including our own recent studies [6,10-14], it appears that the kidney is not simply a victim of chronic maladaptive responses to neurohormonal activation but rather a culprit of the progressing CHF.

It is acknowledged that inappropriate activation of the sympathetic nervous system (SNS) is one of the deleterious processes in patients with CHF [15]. While renal denervation (RDN) (ablation of both afferent and efferent renal nerves) was originally introduced for the treatment of resistant hypertension [16], recent studies indicate that it may be a promising tool for the treatment of CHF [17, 18]. However, despite vast knowledge regarding the important role of SNS in the regulation of kidney function [19], the effects of RDN on kidney function in CHF have been disregarded and all studies were focused on the changes in cardiac function so far $[17,18,20-22]$. Another important limitation of those studies is that a possible beneficial effect of RDN on long-term survival in $\mathrm{CHF}$ has not been explored.

Therefore, the first aim of our present study was to evaluate the effects of RDN on the course of CHF-dependent mortality. The rat with aortocaval fistula (ACF) was employed as a model of CHF: previous studies, including our own, have demonstrated that this model has many features in common with the untreated human CHF [1214]. Therefore, it is now recommended by the American Heart Association as one of golden standard models for testing new therapeutic strategies for CHF [23]. ACF was induced in the Ren-2 transgenic rat (TGR) model, the unique ANG II-dependent model of hypertension that combines endogenous activation of the renin-angiotensin system (RAS) and hypertension [24], the 2 well-recognized important factors promoting the progression of CHF $[2,3,6,7,25,26]$.

To further evaluate our hypothesis that beneficial effects of RDN on the course of ACF-induced CHF are predominantly mediated by renal mechanisms, we assessed the renal function 2 weeks after RDN, that is, 3 weeks after creation of ACF. At this stage, untreated ACF TGR began markedly to die whereas those that underwent RDN exhibited $100 \%$ survival rate. In addition, at the same stage, we evaluated renal vascular responsiveness to
Honetschlagerová et al. 
vasoactive agents in ACF TGR that were or were not subjected to RDN. This was done because we found recently that ACF TGR exhibit altered renal vascular responsiveness to vasoactive agents [14], possibly the mechanism underlying the development of renal dysfunction and acceleration of the progress of $\mathrm{CHF}$ in this hypertensive model.

\section{Methods}

\section{Animals}

All animals used in the present study were bred at the Center of Experimental Medicine of this Institute, from stock animals supplied by the Max Delbrück Center for Molecular Medicine, Berlin, Germany, which is accredited by the Czech Association for Accreditation of Laboratory Animal Care. Heterozygous TGR were generated by breeding male homozygous TGR with female homozygous Hannover-Sprague Dawley (HanSD) rats; agematched HanSD rats served as transgene-negative normotensive controls. The animals were kept on a 12-h/12-h light/dark cycle. Throughout experiments, rats were fed a normal-salt, normal-protein diet $(0.45 \% \mathrm{NaCl}, 19-21 \%$ protein $)$ and had free access to tap water. Male TGR at the initial age of 8 weeks were used for experiments: at this age, TGR are already in the sustained phase of hypertension with blood pressure (BP) levels comparable with those in hypertensive patients (systolic BP [SBP] about $180 \mathrm{~mm} \mathrm{Hg}$ ) and with substantial activation of endogenous RAS, as demonstrated in previous studies including ours. Therefore, the animals seem to be a suitable model for studying the role of hypertension and endogenous RAS in the pathophysiology of CHF [13, 25-27].

Heart Failure Model, Exclusion Criteria, and RDN Technique

Eight-week-old male TGR were anesthetized with an intraperitoneal injection of ketamine/midazolam mixture (Calypsol, Gedeon Richter, Hungary, $160 \mathrm{mg} / \mathrm{kg}$, and Dormicum, Roche, France, $160 \mathrm{mg} / \mathrm{kg}$ ). CHF due to volume overload was then induced by creating an ACF using a needle technique. This procedure is routinely performed in our laboratory, and the details of the technique were reported previously $[13,14]$. Sham-operated rats underwent an identical procedure but without creating ACF. Seven animals in which a technical error occurred during the ACF creation procedure or a pulsatile flow in the inferior vena cava could not be confirmed, suggesting flawed ACF function, were excluded from the study. The representative images of animals that underwent either sham-operation or creation of ACF are given in online suppl. Figure 1; see www.karger.com/doi/10.1159/000513071 for all online suppl. material.

Standard bilateral RDN or sham-RDN procedure was performed 1 week after ACF or sham surgery. Under ketamine/midazolam anesthesia, both kidneys were approached through a midline abdominal incision, both renal arteries and veins were stripped of the connective tissue, and all the visible nerve fibers were separated from the arteries and cut close to the hilus. Then, both renal arteries were painted with a $10 \%$ phenol solution in absolute alcohol in order to destroy any remaining nerve fibers. During the application of phenol, the adjacent tissues were carefully protected from exposure to the phenol solution, and disruption of the major lymphatic vessels in the area was avoided. Six animals $(<5 \%)$ which showed sustained renal artery spasm were excluded from the study. Control animals underwent laparotomy and retraction of the abdominal organs, but renal vessels were not isolated or painted with phenol solution and the renal nerves were not severed; instead, the intra-abdominal area was coated with a $0.9 \% \mathrm{NaCl}$ solution. This procedure of RDN, now employed as a golden standard method of RDN, was repeatedly shown to be fully effective $[19,21,28-30]$.

\section{Detailed Experimental Design}

Series 1: Evaluation of the Effectiveness and Durability of the Effects of RDN in TGR with or without ACF (ACF TGR or Sham-Operated)

Earlier studies have repeatedly shown that renal norepinephrine (NE) concentration is the best marker of renal SNS activity, which is more reliable and robust indicator of an effective RDN than, for example, immunochemistry assessment of tyrosine hydroxylase staining. Renal NE concentration is now considered as a golden neurochemical standard for the evaluation of the effectiveness of RDN method [28-30]. It has been repeatedly shown that within 2-4 days after RDN (performed with the aforementioned method), a depletion of $>90 \%$ of renal NE occurs [19, 21, 28-30]. However, it is now recognized that 9-12 weeks after the described RDN procedure, reinnervation occurs $[16,19,29]$, which limits the possibility to perform long-term studies, for example, those needed to evaluate the effects of RDN on the animals' survival. However, since we know that almost all untreated ACF TGR die between 10 and 15 weeks after induction of ACF [13, 31], effectiveness of the $\mathrm{RDN}$ maintained till week 10 is sufficient for the studies to be performed. Therefore, in this series we evaluated effects of RDN on renal SNS and RAS activity $7,21,42,56,70$, and 84 days $(1,3,6,8$, 10 , and 12 weeks) after RDN ( $n=8$ in each experimental group). The animals underwent either sham-operation or ACF creation as described above (on the day labeled - 7), and on the day 0 , they were randomly assigned to the group that was exposed to $\mathrm{RDN}$ or to sham procedure. At the appropriate time point, the samples for measurement of kidney ANG II (marker of RAS vasoconstrictor axis activity), kidney ANG 1-7 (marker of RAS vasodilator axis activity), and kidney tissue NE (as mentioned above, the golden neurochemical marker of renal SNS activity) were obtained from conscious decapitated rats (it is established that anesthesia substantially alters renal concentrations of those peptides) [24, 32]. The samples were handled as described previously [24, 32]: first, adrenal glands were isolated and removed and the whole kidney tissue was homogenized in $3 \mathrm{~mL}$ of precooled methanol. The kidney ANG II levels were measured by competitive radioimmunoassay (RIA), using the commercially available RIA kit (ED29051; IBL Int., Hamburg, Germany), kidney ANG 1-7 levels were measured by competitive RIA using the custom-made RIA kit (Beckman Coulter, Prague, Czech Republic), and NE levels were measured by a solidphase enzyme-linked immunosorbent assay (ELISA), using the commercially available ELISA kit (RE59395; IBL Int., Hamburg, Germany). All these methods are routinely employed in our laboratory $[13,24,32]$. At each time point, the following groups were examined ( $n=8$ in each experimental group):

1. Sham-operated TGR (without ACF) + intact (without RDN)

2. Sham-operated TGR + RDN

3. ACF TGR + intact

4. $\mathrm{ACF} T \mathrm{TGR}+\mathrm{RDN}$ 
Series 2: Effects of RDN on the Survival Rate

Animals were prepared as described in series 1. Again, on day 0 , either sham-operation or RDN was performed. The following experimental groups were examined:

1. Sham-operated TGR (without ACF) + intact (without RDN) (initial $n=8$ )

2. Sham-operated TGR $+\mathrm{RDN}$ (initial $n=8$ )

3. ACF TGR + intact (initial $n=31$ )

4. ACF TGR + RDN (initial $n=34$ )

In order to obtain reliable data regarding the effects of RDN on the long-term survival rate, relatively high initial $n$ values were used (not so for sham-operated animals). To define the values required, statistical power analysis was performed by the method developed by Cohen [33]. Based on the results of series 1, the follow-up period was up to 70 days, and at the end of experiment, the surviving animals were killed by decapitation and kidney NE concentrations were measured as described above.

Series 3: Effects of RDN on Basal BP, Renal Hemodynamics, Renal Vascular Responsiveness to Vasoactive Agents, and Organ Weight

Animals were prepared as described in series $1(n=8$ in each experimental group), and again on day 0 , either RDN or shamoperation was performed. Two weeks later, the rats were anesthetized with thiopental sodium $(80 \mathrm{mg} / \mathrm{kg}$ i.p.) and prepared for mean arterial pressure (MAP) and RBF measurement as well as for renal artery injections of the agents tested, as described in detail in our recent publication [14]. In brief, the right jugular vein was catheterized with polyethylene (PE50) tubing for the infusion of solutions and intravenous drug administration. The right femoral artery was cannulated for continuous monitoring of arterial BP. The MAP was monitored using a pressure transducer and recorded using a computerized data acquisition system (PowerLab, ADInstruments, UK). The left kidney was exposed via a flank incision, isolated from the surrounding tissue and placed in a lucite cup, and the ureter was cannulated with a PE-10 catheter. For selective intrarenal administration, a tapered PE-10 catheter was inserted into the aorta via the left femoral artery and passed 1-2 mm down the left renal artery. This catheter was kept patent by a continuous infusion of heparinized isotonic saline at a rate of $2 \mu \mathrm{L} / \mathrm{min}$ throughout the experiment. During the surgery, animals received an intravenous infusion of $0.9 \%$ saline solution containing $6 \%$ bovine serum albumin (Sigma Chemical Co., Prague, Czech Republic) at a rate of $20 \mu \mathrm{L} / \mathrm{min}$. With the surgery completed, an isotonic saline solution was infused to compensate for fluid losses. An ultrasonic transient time flow probe (1RB; Transonic Systems, Altron Medical Electronic GmbH, Germany), connected to a Transonic flowmeter, was placed on the left renal artery, and RBF was continuously recorded. After completion of surgery, a 45-min equilibration period was allowed and then 230 -min clearance periods were made as described in detail in our previous studies, to determine initial MAP and renal hemodynamics, that is, basal RBF was assessed as described above and GFR was assessed by employing the polyfructosan (Inutest, Laevosan, Austria) clearance method as described and validated in previous studies [34]. Subsequently, a 10-min equilibration time was allowed, and then renal and systemic vascular responses to vasoactive agents were determined. We used the experimental protocol as in our previous studies [14, 35]: RBF responses to 2 intrarenal doses of ANG II ( 2 and $8 \mathrm{ng}$ ), $\mathrm{NE}$ (20 and $40 \mathrm{ng}$ ), and acetylcholine (Ach) (10 and $40 \mathrm{ng}$ ) were determined. In the same experimental animals, MAP and RBF responses to intravenous doses of ANG II (40 ng) were assessed. Thereafter, the rats received a single injection of losartan (ANG II type 1 receptor antagonist) $(40 \mu \mathrm{g})$ directly into the renal artery, which was followed, with a 5-min delay, by 30-min evaluation of RBF. Preliminary studies indicated that this dose of losartan is sufficient to prevent renal vasoconstrictor effects of an intrarenal bolus injection of ANG II and it did not spill over to the systemic circulation in amounts sufficient to produce significant decreases in MAP or to attenuate systemic BP responses to intravenous injection of ANG II. At the end of experiment, MAP and RBF responses to intrarenal bolus administration of $8 \mathrm{ng}$ of ANG II and intravenous bolus administration of $40 \mathrm{ng}$ of ANG II were determined again, to confirm the action of intrarenal administration of losartan on the renal and systemic circulation. At the end, first the whole heart weight and then left ventricle weight(LVW) (including septum), right ventricle weight (RVW), and lung weight were assessed as described in our previous studies [13, 14, 31, 35]. In case of the lungs, the so-called "wet lung weight" was assessed, that is, the excised lung was only gently pressed and left for $5 \mathrm{~min}$ on the suction filter paper. This method is consistently used in our laboratory and enables comparison of the effects of various treatment regimens on the degree of cardiac hypertrophy and lung congestion in the ACF model of CHF.

Series 4: Effects of RDN on the Right Ventricle Systolic Pressure Measured by the Invasive Hemodynamic Method

Animals were prepared as described in series 1. Again, on day 0 , either sham-operation or RDN was performed, and 2 weeks later, the rats underwent invasive hemodynamic evaluation as described in our previous studies, however, modified in way to enable evaluation of right ventricle systolic pressure (RVSP), as a surrogate to pulmonary pressure overload [13]. In brief, the rats were anesthetized with $2 \%$ isoflurane (Aerrane, Baxter, SA, USA) and were subjected to right ventricle catheterization through the right jugular vein to measure RVSP using the curved microtip pressure transducer SPR-513 (Millar, Houston, TX, USA) connected via the control unit TC-510 to the bridge amplifier 660 (Hugo Sachs Elektronik, March, Germany) and a PC computer. Using our custommade software, peak systolic pressure and heart rate values were averaged from 3 measurements, each comprising 10 cardiac cycles.

The following experimental groups were examined:

1. Sham-operated TGR + intact $(n=8)$

2. Sham-operated TGR $+\mathrm{RDN}(n=9)$

3. ACF TGR $+\operatorname{intact}(n=11)$

4. $\mathrm{ACF} T \mathrm{TGR}+\mathrm{RDN}(n=11)$

Series 5: Effects of RDN on the Kidney Messenger Ribonucleic Acid and Protein Expression of ANG II and Adrenergic Receptors and Characterization of Adrenergic Receptors Using Ligand Binding Studies

Animals were prepared as described in series 1. Again, on day 0 , either sham-operation or RDN was performed, and 2 weeks later, animals were euthanized by decapitation. The following experimental groups were examined ( $n=9$ in each group):

1. Sham-operated TGR + intact

2. Sham-operated TGR + RDN

3. ACF TGR + intact

4. $\mathrm{ACF} T \mathrm{TGR}+\mathrm{RDN}$
Honetschlagerová et al. 
The kidneys were removed, and the messenger ribonucleic acid (mRNA) expression for $\mathrm{AT}_{1}$ receptors, $\mathrm{ANG}$ II type $2\left(\mathrm{AT}_{2}\right)$ receptors, adrenergic receptors $\alpha$ type 1 (specifically subtypes $\alpha 1 \mathrm{a}, \alpha 1 \mathrm{~b}$, and $\alpha 1 \mathrm{~d}$ ), adrenergic receptors $\alpha$ type 2 (subtypes $\alpha 2 \mathrm{a}, \alpha 2 \mathrm{~b}$, and $\alpha 2 c)$, adrenergic receptors $\beta$ type 1 ( $\beta 1$ ), and adrenergic receptors $\beta$ type $2(\beta 2)$ were assessed in the kidney cortex. The relative mRNA expression was calculated by the $\Delta \Delta C t$ method as described in detail in our previous study [36], and the results were expressed as the $\mathrm{n}$-fold difference in gene expression relative to GAPDH mRNA and control (i.e., noninduced) group, as was performed in our previous studies [36]. The primers were designed by Primer3 software and purchased from Generi Biotech Ltd. (Hradec Králové, Czech Republic). Individual primer sequences are available in online suppl. file 1 .

Western blot analyses for protein expression of $\mathrm{AT}_{1}, \mathrm{AT}_{2}, \alpha 1$, $\alpha 2(\alpha 2 a, \alpha 2 b$, and $\alpha 2 c), \beta 1$, and $\beta 2$ receptors in the kidney cortex were performed as described previously $[34,36]$, with levels normalized to $\beta$-actin (for more details, see online suppl. file 1 ). In addition, to obtain deeper insight into the effects of RDN on renal vascular responsiveness to vasoactive agents, ligand binding studies were employed to further characterize adrenergic receptors $\alpha 1$ and $\beta$ in the crude membrane isolated from the kidney cortex (for more details, see online suppl. file 1).

\section{Statistical Analysis}

Statistical analysis of the data was performed using GraphPad Prism 7 (GraphPad Software, San Diego, CA, USA). Comparison of survival curves was performed by the log-rank (Mantel-Cox) test followed by the Gehan-Breslow-Wilcoxon test. Statistical comparison of other results was made by Student's $t$ test, Wilcoxon's signed-rank test for unpaired data, or 1-way ANOVA when appropriate. The values are expressed as mean \pm SEM; $p<$ 0.05 was considered to indicate a statistically significant difference.

\section{Results}

Series 1: Evaluation of the Effectiveness and Durability of the Effects of RDN in TGR with or without ACF (ACF TGR or Sham-Operated)

Figure $1 \mathrm{~A}$ shows that 70 days after RDN, the kidney NE concentrations were substantially reduced (by $>90 \%$ ), both in sham-operated and in ACF TGR, and the same was true for the data obtained 7, 21, 42, and 56 days after RDN. On the other hand, on day 84 , the kidney NE concentrations were reduced only by about $40 \%$ (data are shown in online suppl. Fig. 2a).

As shown in Figure 1B, the kidney ANG II concentrations in ACF TGR were markedly higher than in shamoperated TGR and RDN did not alter them in either group. These data represent values obtained 70 days after $\mathrm{RDN}$, but the same was true for all the other time points (i.e., 7, 21, 42, 56, and 84 days after RDN) (data are shown in online suppl. Fig. 2b).

Renal Denervation in Heart Failure Rats
A

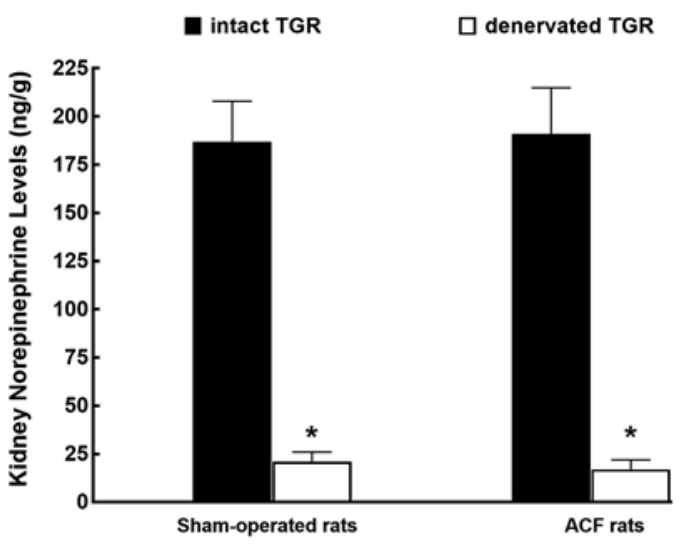

B

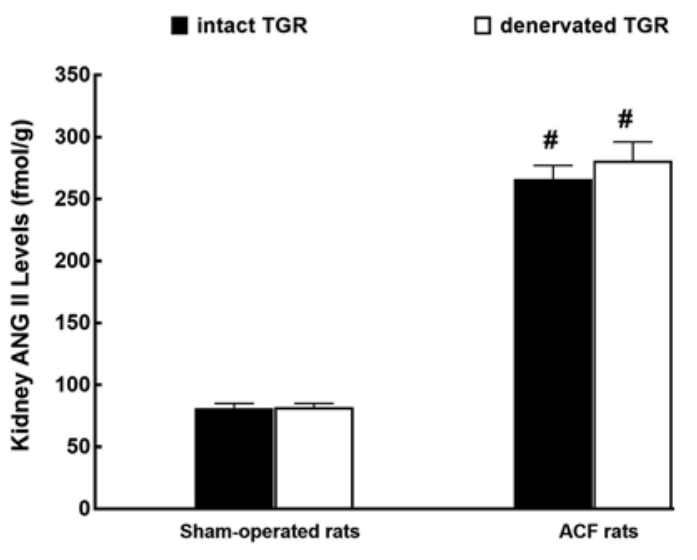

C

intact TGR

$\square$ denervated TGR

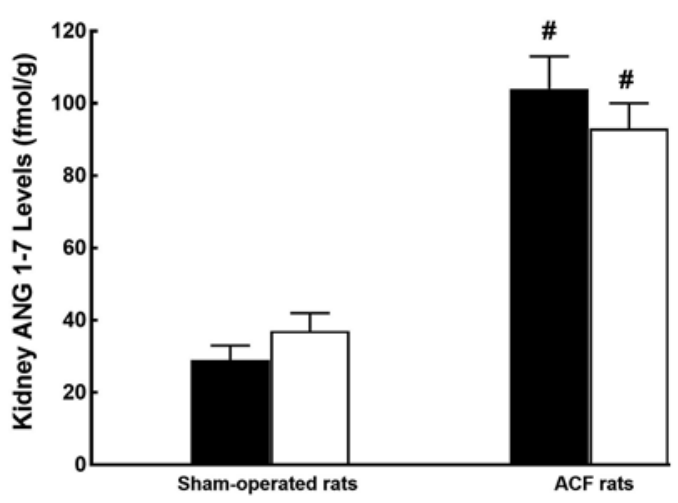

Fig. 1. Kidney norepinephrine (A), kidney ANG II (B), and kidney ANG 1-7 levels (C) in intact, that is, nondenervated (solid bars), and denervated (open bars) heterozygous Ren-2 TGR that were either with $\mathrm{ACF}$ or sham-operated, studied 70 days after renal denervation. Presented data relate to series 1 , in which only the effectiveness and durability of renal denervation were evaluated. ${ }^{*} p<0.05$ versus intact TGR. ${ }^{\#} p<0.05$ versus sham-operated TGR. All the values shown are means \pm SEM. TGR, transgenic rats; ANG 1-7, angiotensin 1-7; ANG II, angiotensin II; ACF, aortocaval fistula.

Kidney Blood Press Res 2021;46:95-113 


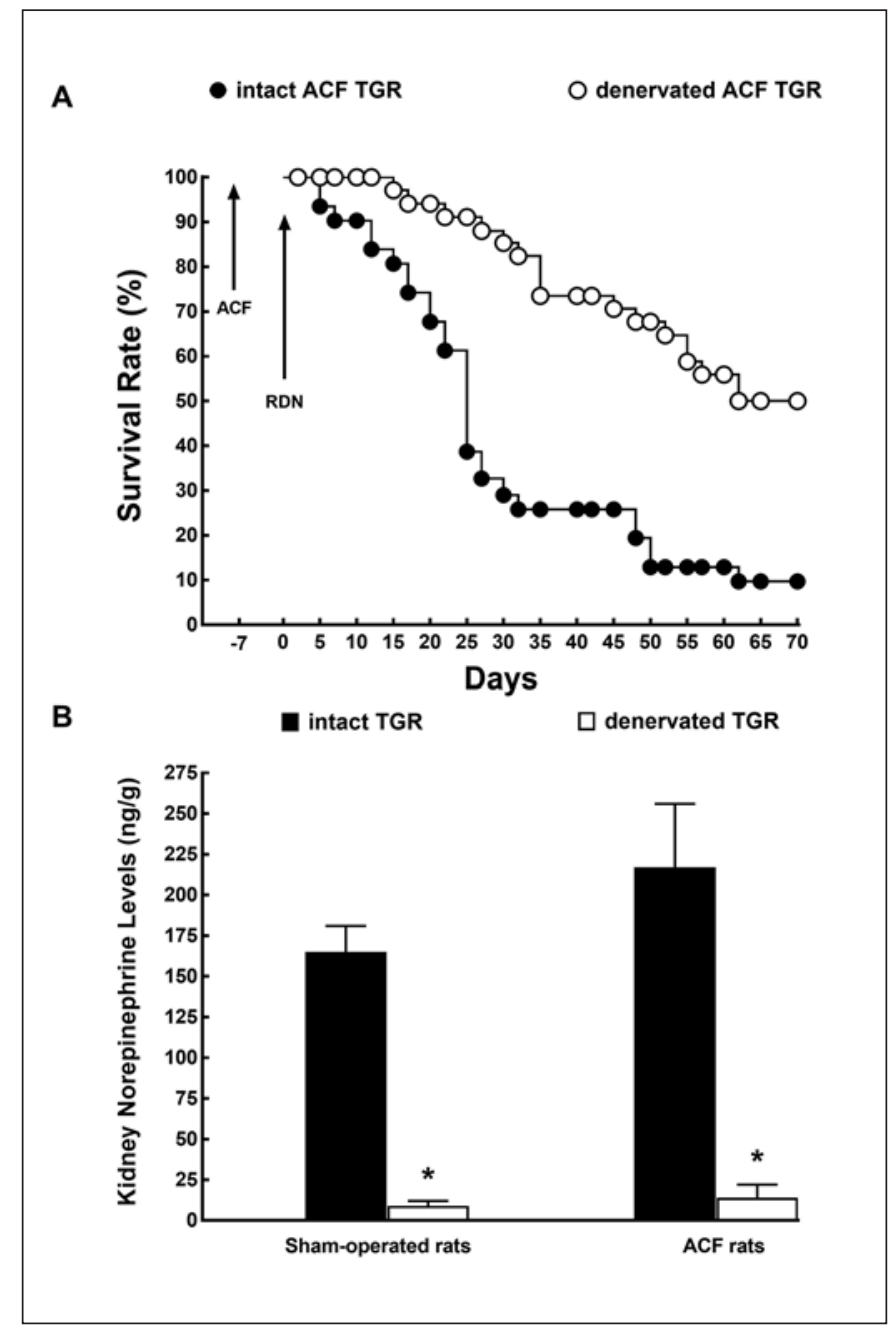

Fig. 2. A Survival rates in intact (solid circles) and denervated (RDN) (open circles) heterozygous Ren-2 TGR with ACF. B Kidney norepinephrine levels in intact, that is, nondenervated (solid bars), and denervated (open bars) TGR that were either with ACF or sham-operated, studied at the end of experiment. Norepinephrine levels presented in this figure were measured in rats from series 2 , in which the effects of renal denervation on the survival rate was evaluated (i.e., these data confirm the effectiveness of renal denervation in animals that survived until the end of experiment). ${ }^{*} p<0.05$ versus intact TGR. All the values shown are means \pm SEM. TGR, transgenic rats; ACF, aortocaval fistula.

Likewise, kidney ANG 1-7 concentrations in intact (nondenervated) ACF TGR were significantly higher than in intact sham-operated (without ACF) TGR, and RDN did not alter this pattern (Fig. 1C). On the whole, data summarized in Figure 1 and online suppl. Figure 2 indicate that in $\mathrm{ACF}$, model of $\mathrm{CHF}, \mathrm{RDN}$ is fully effective for at least 70 days and it does not directly alter intrarenal RAS activity.
Series 2: Effects of RDN on the Survival Rate

As shown in Figure 2A, the nondenervated (i.e., intact) ACF TGR began to die by day +14 (i.e., 21 days after creation of ACF) and the final survival rate was $9.7 \%$ ( 3 of the total of 31 rats). RDN markedly improved the survival rate, and the final value was 50\% (17/34). All the sham-operated TGR (without ACF), both intact and denervated, survived until the end of the experiment (data not shown).

Figure $2 \mathrm{~B}$ shows that RDN dramatically reduced kidney NE concentration when measured at the end of this protocol, that is, 70 days after $\mathrm{RDN}$, similarly in shamoperated (without ACF) rats (to $4 \%$ of the value for intact rats) and in ACF TGR (to 5\%). These data that were evaluated at the end of experiment confirmed the effectiveness of the RDN procedure used in the survival animals.

Series 3: Effects of RDN on Basal BP, Renal

Hemodynamics, Renal Vascular Responsiveness to Vasoactive Agents, and Organ Weight

Figure 3 collects the data on the basal MAP, RBF, renal vascular resistance (RVR), and GFR measured in rats 3 weeks after creation of ACF (or sham-operation) and 2 weeks after RDN (or in nondenervated intact animals). A creation of ACF resulted in decreases in MAP then in sham-operated TGR, and RDN did not alter MAP in ACF TGR. In contrast, RDN in sham-operated TGR (without $\mathrm{ACF}$ ) resulted in a significant decrease in MAP when compared with their nondenervated (intact) counterparts (137 \pm 2 vs. $165 \pm 2 \mathrm{~mm} \mathrm{Hg}, p<0.05)$ (Fig. 3A). Basal RBF was significantly lower in ACF TGR than in sham-operated TGR, and RDN did not alter it in any group (Fig. 3B). However, RVR was not significantly elevated in intact ACF TGR as compared with intact shamoperated TGR. RDN decreased RVR in sham-operated TGR, but did not alter it in ACF TGR (Fig. 3C). There were no significant differences in GFR between intact sham-operated and ACF TGR, and RDN did not alter it in any group (Fig. 3D).

As shown in Figure $4 \mathrm{~A}-\mathrm{C}$, intact (nondenervated) ACF TGR exhibited marked bilateral cardiac hypertrophy as seen from whole heart weight, LVW (with septum), and RVW as compared with the intact sham-operated (without ACF) TGR. Interestingly, the degree of right ventricle hypertrophy was in all ACF TGR higher than that of the left ventricle, as documented by the increases in RVW to LVW ratio (Fig. 4D). In addition, intact ACF TGR showed significantly higher lung weight as compared with intact sham-operated TGR, indicating the development of important lung congestion in the former 
A

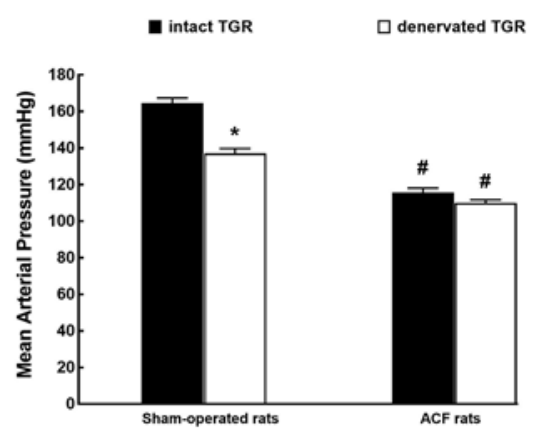

B

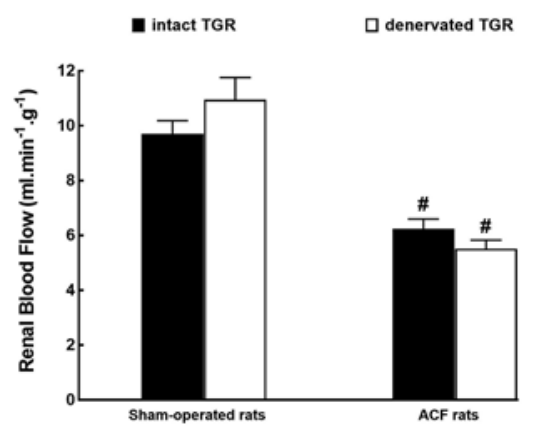

C

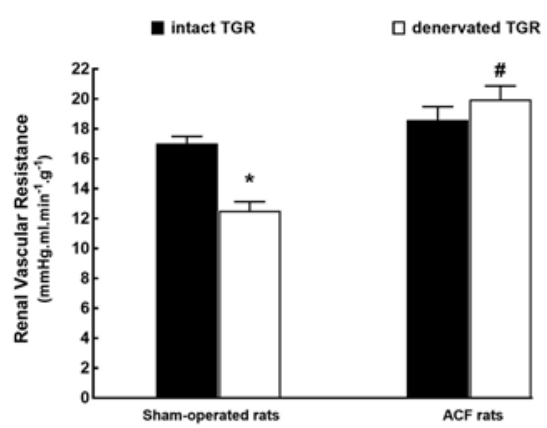

D

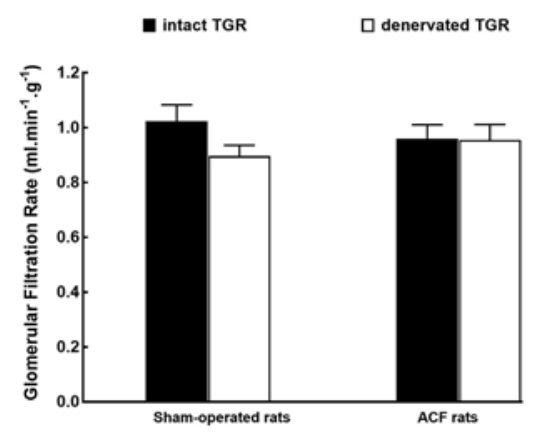

Fig. 3. Mean arterial pressure (A), renal blood flow (B), renal vascular resistance (C), and glomerular filtration rate (D) in intact, that is, nondenervated (solid bars), and denervated (open bars) TGR that were either with ACF (right-hand side) or sham-operated (left). ${ }^{*} p<0.05$ versus intact TGR. ${ }^{*} p<0.05$ versus sham-operated TGR. All the values shown are means \pm SEM. TGR, transgenic rats; ACF, aortocaval fistula.

(Fig. 4E). RDN in sham-operated TGR did not alter any of the parameters. In contrast, in the ACF TGR group, RDN significantly reduced the whole heart weight, LVW, RVW, and lung weight (Fig. 4A-E). To confirm these results, we performed more complex analysis of the cardiac morphometry and morphology, summarized in online suppl. Figure 3, which depicts gross morphological characteristics of the whole heart (panels a-d) and representative whole slide histologic images of the heart cross sections (at the papillary muscle level) from the same experimental groups (panels e-h). RDN did not significantly reduce the whole heart weight in sham-operated TGR. On the other hand, intact ACF TGR revealed marked cardiac hypertrophy as compared with intact sham-operated TGR and RDN in ACF TGR significantly reduced the whole heart weight. In addition, the histology examination showed that intact ACF TGR exhibited signs of eccentric hypertrophy of both ventricles and no significant fibrosis, signs of acute ischemic changes, or inflammatory infiltration were observed in any of the groups.

Renal Denervation in Heart Failure Rats
There were no significant differences between intact sham-operated TGR and intact ACF TGR in body weight ( $432 \pm 14$ vs. $439 \pm 12$ g), kidney weight (1.69 \pm 0.04 vs. $1.64 \pm 0.05 \mathrm{~g}$ ), and liver weight ( $16.01 \pm 0.92$ vs. $16.37 \pm 1.06 \mathrm{~g}$ ), and RDN did not alter organ weights in any group. Figure $5 \mathrm{~A}$ illustrates the maximum decreases in RBF induced by intrarenal administration of 2 and $8 \mathrm{ng}$ of ANG II, and it shows that the responses were substantially greater in nondenervated (intact) ACF TGR as compared with intact sham-operated (without ACF) TGR. RDN did not alter RBF responses to the lower dose of ANG II (2 ng) either in sham-operated TGR or ACF TGR. However, RDN significantly increased the response (greater RBF decreases) in shamoperated TGR as well as ACF TGR to the higher ANG II dose (8 ng).

Figure 5B shows that intrarenal administration of $\mathrm{NE}$ at the doses of 20 and $40 \mathrm{ng}$ elicited similar dose-dependent RBF decreases in intact sham-operated and ACF TGR. In both groups, RDN significantly increased RBF 
A

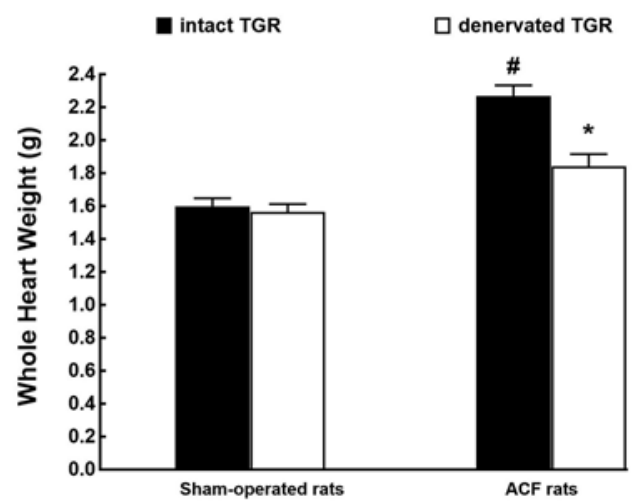

B

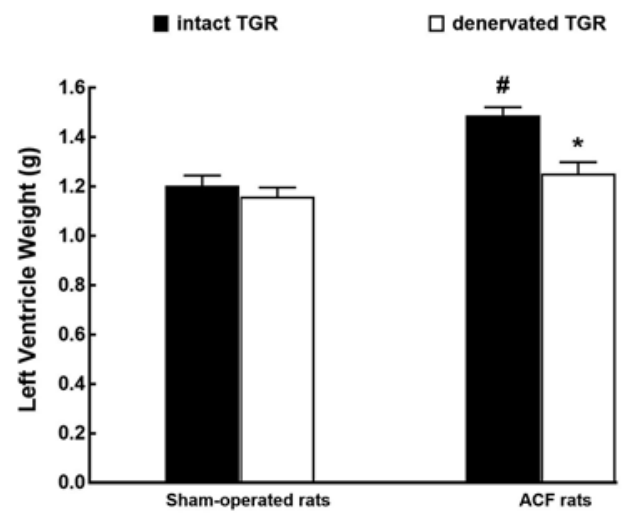

C

a intact TGR

$\square$ denervated TGR

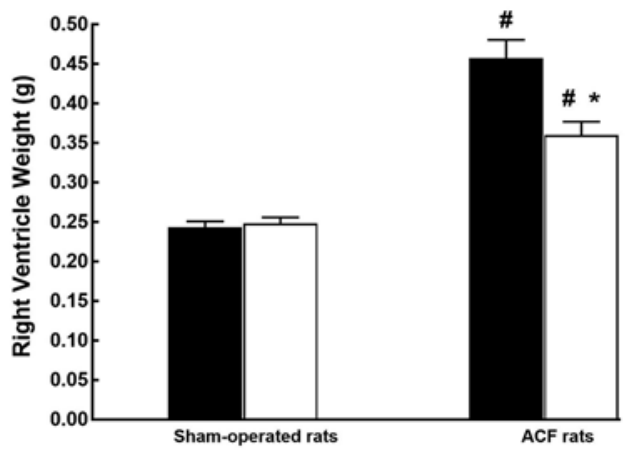

D

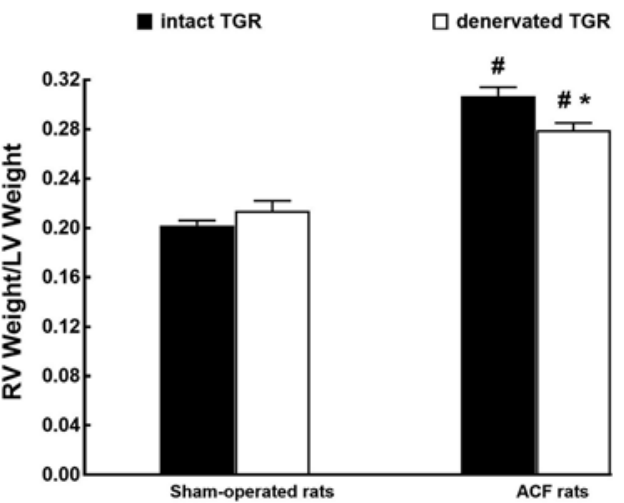

E

intact TGR

$\square$ denervated TGR

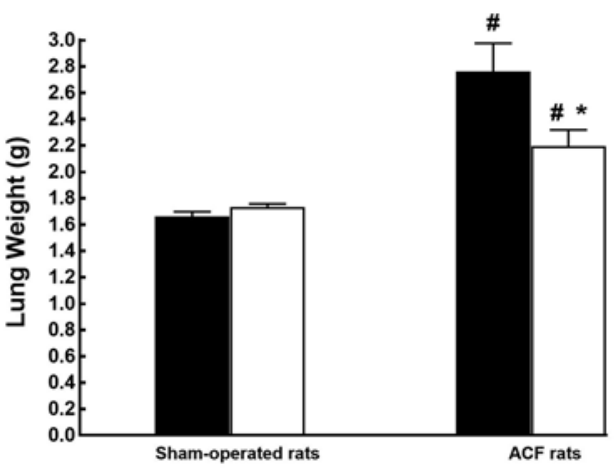

Fig. 4. Whole heart weight (A), LV weight (B), RV weight (C), the ratio of RV weight to LV weight (D), and lung weight (E) in intact, that is, nondenervated (solid bars), and denervated (open bars) TGR that were either with $\mathrm{ACF}$ (right-hand side) or sham-operated (left). Presented results were obtained in the third series of experiments. ${ }^{*} p<0.05$ versus intact TGR. ${ }^{*} p<0.05$ versus sham-operated TGR. All the values shown are means \pm SEM. LV, left ventricle; RV, right ventricle; TGR, transgenic rats; $\mathrm{ACF}$, aortocaval fistula. 
responses (greater decreases) to intrarenal NE as compared with the intact counterparts. However, these RBF decreases after RDN were markedly greater in ACF TGR as compared with sham-operated TGR.

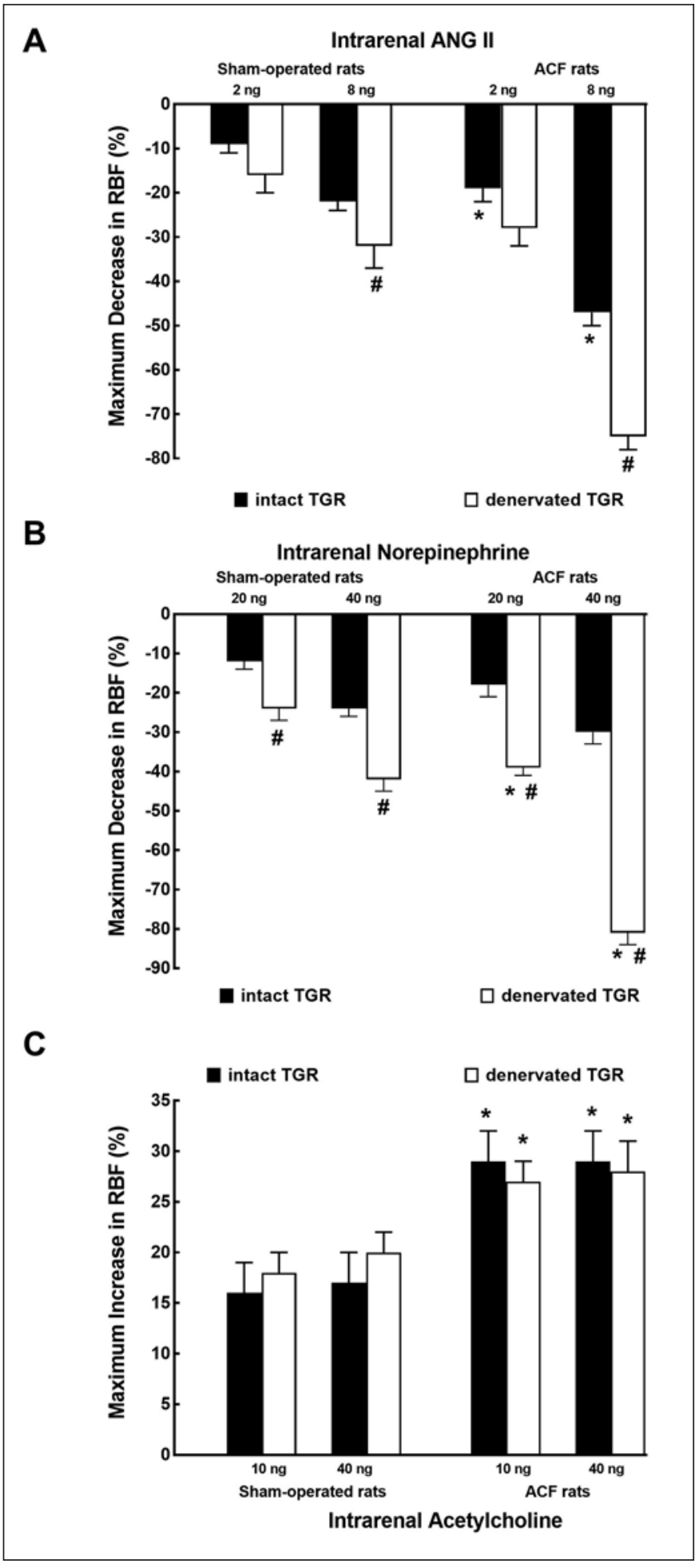

Renal Denervation in Heart Failure Rats
As shown in Figure 5C, intrarenal administration of 10 and $40 \mathrm{ng}$ of Ach elicited significantly greater increases in RBF in intact (nondenervated) ACF TGR as compared with intact sham-operated TGR. RDN did not modify the $\mathrm{RBF}$ responses to Ach in any group.

Figure $6 \mathrm{~A}$ and $\mathrm{b}$ shows that intravenous bolus administration of ANG II elicited substantially smaller increase in MAP in intact (nondenervated) ACF TGR than in intact sham-operated (without ACF) TGR, whereas the RBF decrease was similar. RDN did not significantly alter the MAP and RBF responses to intravenous ANG II. Figure $6 \mathrm{C}$ shows MAP response to ANG II administration 45 min after intrarenal administration of losartan, which was almost identical as before its administration (illustrated in Fig. 6A). This indicates that losartan (at the used dose) did not permeate into the systemic circulation in sufficient amount to produce a significant blockade of extrarenal $\mathrm{AT}_{1}$ receptors for ANG II. As shown in Figure $6 \mathrm{D}$, intrarenal administration of losartan elicited distinct increase in RBF in intact (nondenervated) sham-operated TGR as well as in intact ACF TGR; however, this increase was markedly higher in the latter. RDN did not alter RBF responses to intrarenal losartan in any group.

\section{Series 4: Effects of RDN on RVSP}

As shown in Figure 7A, the increased RVW to LVW ratio in ACF TGR indicates that in ACF TGR, right ventricle hypertrophy was greater than the left ventricle hypertrophy. RDN did not alter this ratio in sham-operated TGR, but significantly reduced it in ACF TGR. These results are in agreement with data obtained in the third series of experiments (summarized in Fig. 4D) and further support our notion that the degree of right ventricle hypertrophy in all ACF TGR is higher than that of the left ventricle.

Figure 7B shows that intact ACF TGR exhibited significantly higher RVSP as compared with intact sham-operated TGR $(37.1 \pm 0.5$ vs. $26.2 \pm 0.4 \mathrm{~mm} \mathrm{Hg}$, respectively; $p<0.05)$. RDN did not change RVSP in sham-operated TGR, however significantly decreased it in ACF TGR.

Fig. 5. Maximum change in the RBF induced by intrarenal bolus administration of ANG II (2 and $8 \mathrm{ng}$ ) (A), norepinephrine (20 and $40 \mathrm{ng}$ ) (B), and acetylcholine (10 and $40 \mathrm{ng}$ ) (C) in intact, that is, nondenervated (solid bars), and denervated (open bars) TGR that were either with ACF (right-hand side) or sham-operated (left). ${ }^{*} p<0.05$ versus sham-operated rats for the same dose. ${ }^{*} p<0.05$ versus intact counterparts for the same dose. All the values shown are means \pm SEM. RBF, renal blood flow; ANG II, angiotensin II; TGR, transgenic rats; ACF, aortocaval fistula. 
A

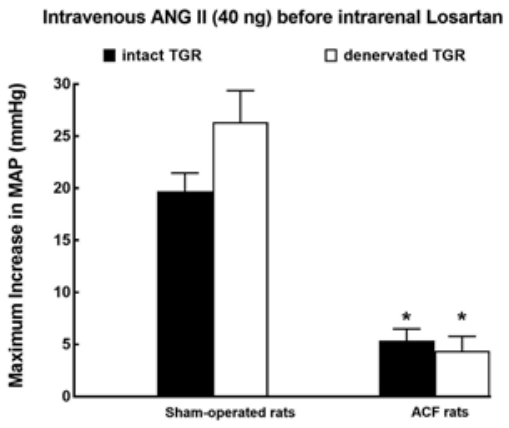

B

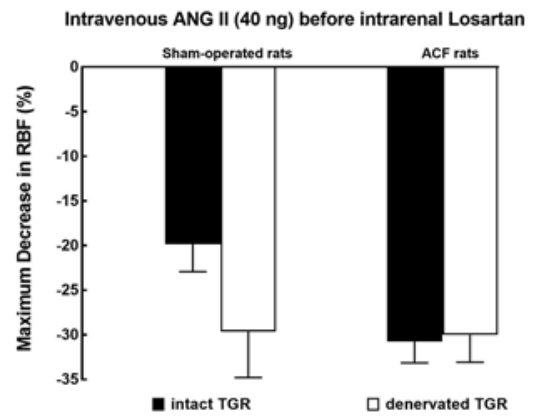

C

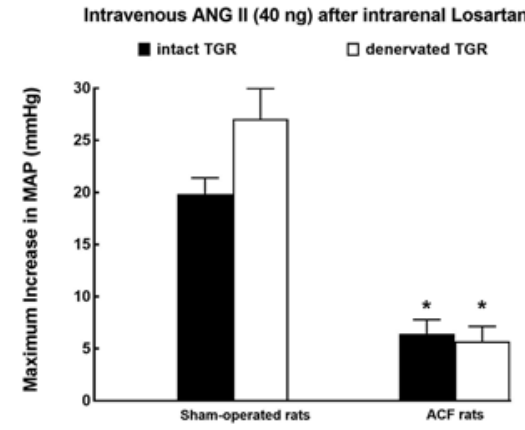

D

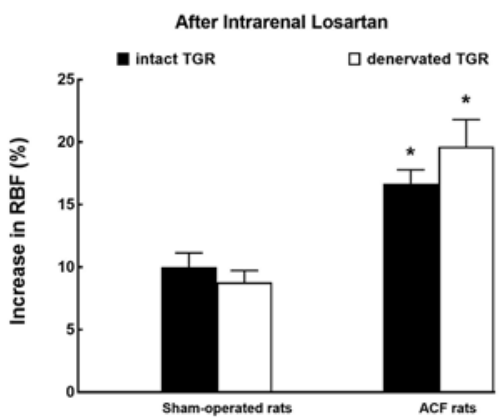

Fig. 6. Maximum change in MAP elicited by intravenous bolus administration of ANG II (40 ng) before (A) and after (C) intrarenal losartan (AT1 receptor antagonist) administration; (B) maximum decrease in RBF elicited by intravenous bolus administration of ANG II (40 ng) before intrarenal losartan and (D) RBF increase after intrarenal administration of losartan in intact, that is, nondenervated (solid bars), and denervated (open bars) TGR that were either with ACF (right-hand side) or sham-operated (left). ${ }^{*} p<0.05$ versus sham-operated rats. All the values shown are means \pm SEM. MAP, mean arterial pressure; RBF, renal blood flow; ANG II, angiotensin II; TGR, transgenic rats; ACF, aortocaval fistula.

Table 1. Binding characteristics of adrenergic receptors in the crude membrane isolated from the kidney cortex

\begin{tabular}{|c|c|c|c|c|}
\hline & $\begin{array}{l}\text { Intact sham-operated } \\
\text { TGR }\end{array}$ & $\begin{array}{l}\text { Sham-operated } \\
\text { TGR + RDN }\end{array}$ & $\begin{array}{l}\text { ACF TGR + } \\
\text { intact }\end{array}$ & $\begin{array}{l}\mathrm{ACF} T G R+ \\
\mathrm{RDN}\end{array}$ \\
\hline \multicolumn{5}{|l|}{$\alpha 1 A R$} \\
\hline$B_{\max }(\mathrm{fmol} / \mathrm{mg}$ of protein $)$ & $103 \pm 2$ & $105 \pm 3$ & $107 \pm 2$ & $103 \pm 2$ \\
\hline$K_{\mathrm{D}}(\mathrm{pM})$ & $352 \pm 21$ & $331 \pm 11$ & $361 \pm 4$ & $349 \pm 14$ \\
\hline \multicolumn{5}{|l|}{$\beta A R$} \\
\hline$B_{\max }(\mathrm{fmol} / \mathrm{mg}$ of protein $)$ & $23.1 \pm 0.8$ & $21.5 \pm 0.7$ & $23.6 \pm 0.8$ & $22.7 \pm 0.9$ \\
\hline$K_{\mathrm{D}}(\mathrm{pM})$ & $271 \pm 20$ & $225 \pm 29$ & $238 \pm 20$ & $212 \pm 19$ \\
\hline
\end{tabular}

Values are given as means \pm SEM from 3 experiments performed in triplicates in case of $\alpha 1$ AR and from 4 experiments in case of $\beta$ AR. AR, adrenergic receptors; TGR, transgenic rats; ACF, aortocaval fistula; RDN, renal denervation; $B_{\max }$, maximal binding capacity; $K_{\mathrm{D}}$, equilibrium dissociation constant. 
A

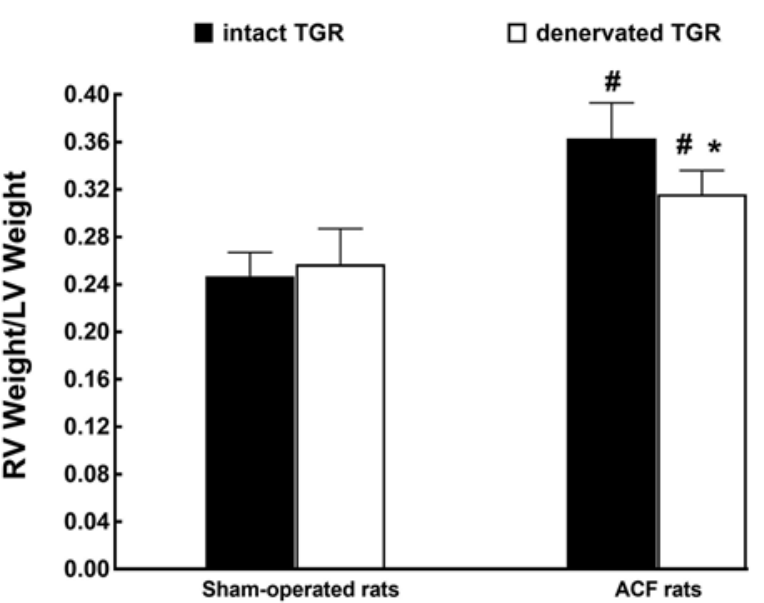

B

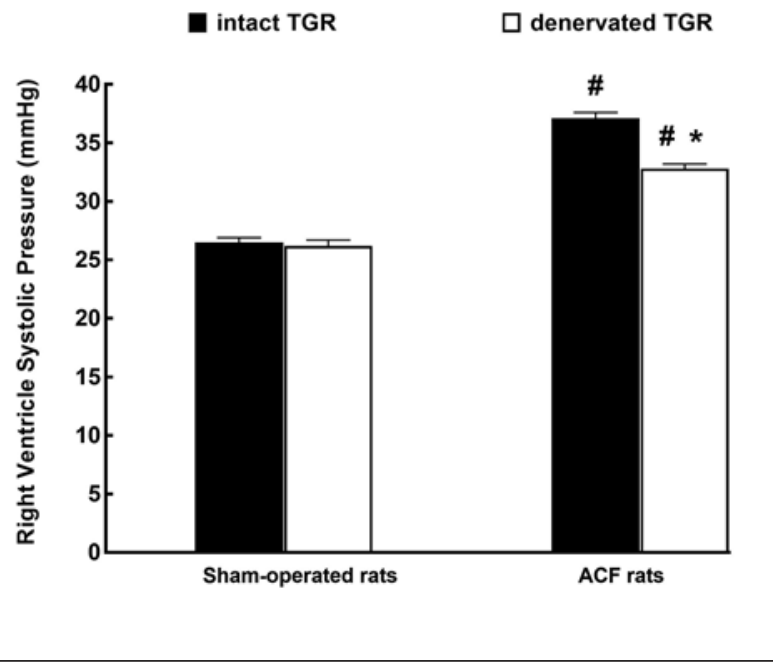

Fig. 7. The ratio of RV to LV weight (A) and RV systolic pressure (B) in intact, that is, nondenervated (solid bars), and denervated (open bars) TGR that were either with ACF (right-hand side) or sham-operated (left). Presented results were obtained in the fourth series of experiments. ${ }^{*} p<0.05$ versus intact TGR. ${ }^{*} p<0.05$ versus sham-operated TGR. All the values shown are means \pm SEM. LV, left ventricle; RV, right ventricle; TGR, transgenic rats; ACF, aortocaval fistula.

Series 5: Effects of RDN on the Kidney $m R N A$ and Protein Expression of ANG II and Adrenergic

Receptors and Characterization of Adrenergic

Receptors Using Ligand Binding Studies

Figure 8 presents mRNA and protein expressions of $\mathrm{AT}_{1}$ and $\mathrm{AT}_{2}$ receptors in the kidney cortex. As shown in Figure $9 \mathrm{~A}$ and $\mathrm{B}$, there were no significant differences in mRNA expression between intact sham-operated TGR and ACF TGR. RDN increased the gene expression of kidney $\mathrm{AT}_{1}$ and $\mathrm{AT}_{2}$ receptors in sham-operated TGR, but did not alter it in ACF TGR. As shown in Figure 9C and $\mathrm{d}$, protein expression of $\mathrm{AT}_{1}$ and $\mathrm{AT}_{2}$ receptors did not significantly differ between intact sham-operated and ACF TGR and RDN did not modify them, similarly in sham-operated and ACF TGR.

Figure 9 summarizes the mRNA expression of $\alpha 1 \mathrm{a}$, $\alpha 1 b$, and $\alpha 1 \mathrm{~d}$ subtypes of adrenergic receptor and the protein expression of $\alpha 1$ (all subtypes) adrenergic receptor. The most important finding is shown in Figure 9D: there were no significant differences in the kidney protein expression of al receptor between intact sham-operated TGR and ACF TGR and RDN did not change them, similarly in sham-operated and ACF TGR. There were no significant differences in the mRNA and protein expression of $\alpha 2$ adrenergic receptors ( $\alpha 2 a, \alpha 2 b$, and $\alpha 2 c$ subtypes) between all experimental groups (data not shown).

Online suppl. Figure 4 summarizes the kidney mRNA and protein expression of $\beta 1$ and $\beta 2$ adrenergic receptors. There were no significant differences between intact sham-operated TGR and ACF TGR, and RDN did not change the gene and protein expression of $\beta 1$ and $\beta 2$, similarly in sham-operated and ACF TGR.

As summarized in Table 1, the total amount and affinity of $\alpha 1$ and $\beta$ adrenergic receptors in crude membrane fractions did not significantly differ between sham-operated TGR and ACF TGR and RDN did not alter them in sham-operated or ACF TGR. Representative binding curves for $\alpha 1$ and $\beta$ adrenergic receptors are shown in online suppl. Figure $3 \mathrm{a}$ and $\mathrm{b}$. As shown in online suppl. Table 1, the proportion of $\beta 2$ adrenergic receptors did not significantly differ between intact sham-operated TGR and ACF TGR. RDN did not alter this ratio in sham-operated TGR, but caused a slight but significant increase in ACF TGR. Nevertheless, the affinities of the selective $\beta 2$ adrenergic antagonist ICI 118,551 to $\beta 2$ and $\beta 1$ adrenergic receptors were almost identical in all experimental groups (online suppl. file 1 and online suppl. Fig. 3c).

\section{Discussion}

The main finding of our present study is that RDN substantially attenuated CHF-dependent mortality in ACF TGR. This is of critical importance because ACFinduced CHF is the model in which the interplay between the heart and kidney is crucial for the progression of $\mathrm{CHF}$ [12-14, 27, 31, 35]. Moreover, in ACF TGR, 2 additional detrimental factors are present: hyperactivity of the RAS and hypertension $[2,7,25,26]$, both present before the 
A

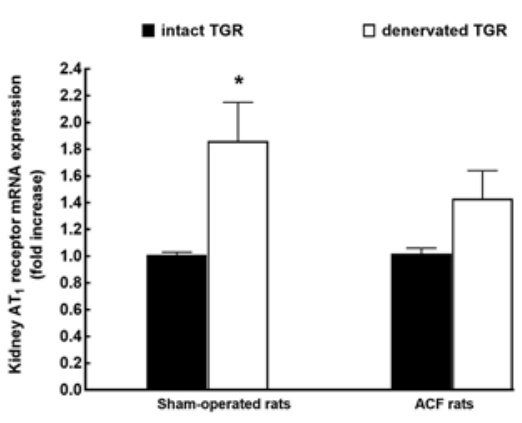

B

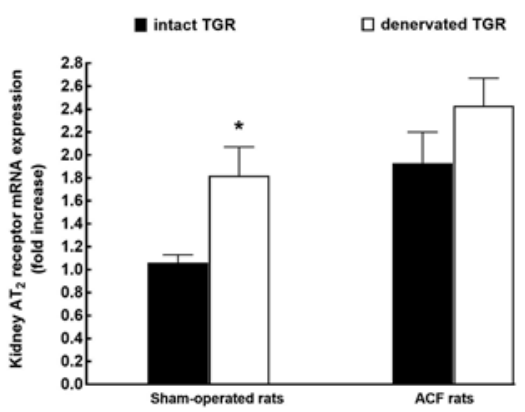

C

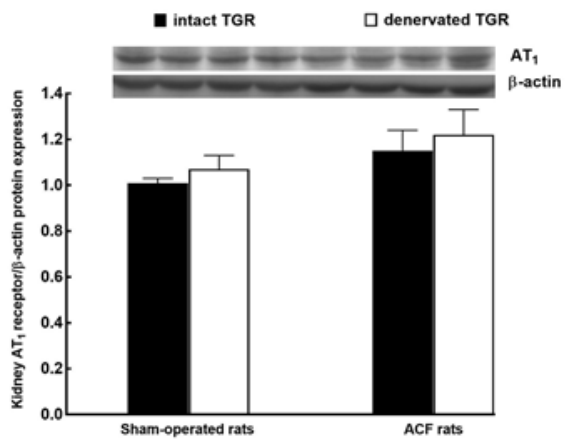

D

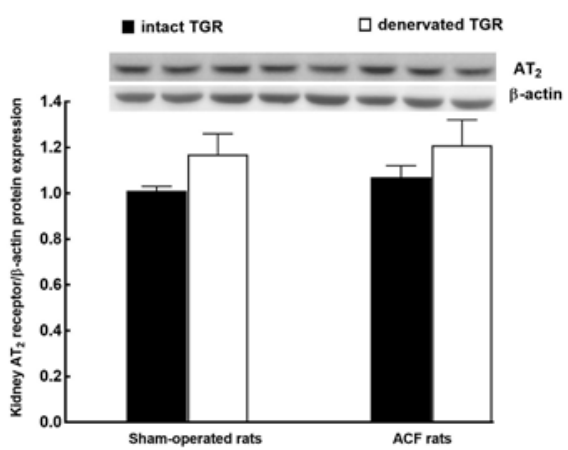

Fig. 8. Kidney angiotensin II receptor type $1\left(\mathrm{AT}_{1}\right)$ mRNA $(\mathbf{A})$ and protein $(\mathbf{C})$ expression and kidney angiotensin II type 2 receptor $\left(\mathrm{AT}_{2}\right)$ mRNA (B) and protein (D) expression in intact, that is, nondenervated (solid bars), and denervated (open bars) TGR that were either with ACF (right-hand side) or sham-operated (left). Representative blots are shown above panels $\mathbf{C}$ and $\mathbf{D} .{ }^{*} p<0.05$ versus intact TGR. All the values shown are means \pm SEM. mRNA, messenger ribonucleic acid; TGR, transgenic rats; ACF, aortocaval fistula.

onset of CHF. Therefore, ACF TGR seems to be optimal model for evaluation of cardiorenal interaction, which in human medicine is known as "cardiorenal syndrome" [6]. To our knowledge, we are the first to show that RDN improves survival rate in the ACF model of CHF.

While the term "cardiorenal syndrome" is a simplification as it encompasses a spectrum of disorders involving the heart and the kidney [6], there is no doubt that reduced RBF, GFR, and the development of renal dysfunction augur poor outcome in patients with $\mathrm{CHF}[37,38]$. It has even been proposed that GFR decrease is an independent predictor of high mortality in CHF patients, more important than, for instance, reduction of LV ejection fraction or the indices included in the New York Heart Association functional class [7, 39]. Unfortunately, despite the progress in the focused therapy in patients with "cardiorenal syndrome," the renal dysfunction can hardly be prevented and the survival prognosis remains bleak $[2,6,7]$, which calls for the development of new therapeutic measures. Therefore, the present clear demonstration that RDN can substantially improve longterm survival in ACF TGR is of special value. In this connection, understanding the mechanism(s) underlying the beneficial effects is of primary importance.

First, we would like to address the finding that GFR in ACF TGR was not decreased as compared with the healthy sham-operated counterparts. Previous studies using the MI-induced CHF model also reported that in the compensated phase of HF, the RBF was decreased and GFR was maintained in the physiological range [11]. It was demonstrated to be the result of preferential ANG II vasoconstriction in the efferent arteriole. Our present findings suggest that more pronounced increase in the postglomerular vascular resistance could be the cause of the reduced RBF but maintained GFR. However, the changes in the filtration fraction alone cannot be used as unequivocal index of the localization of resistance changes in the glomerular circulation [40]. Evidently, renal micropunc- 
A

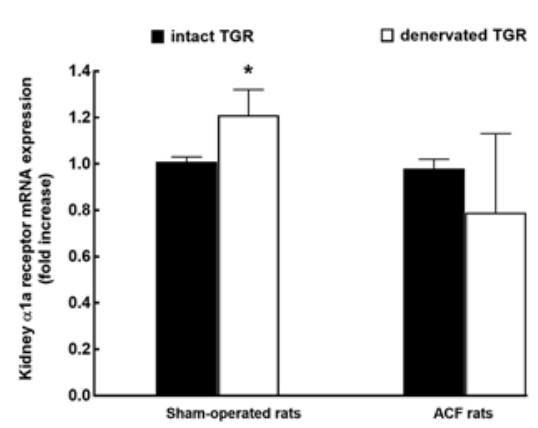

B

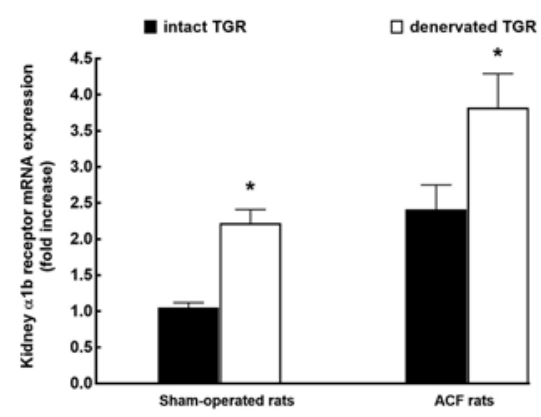

C

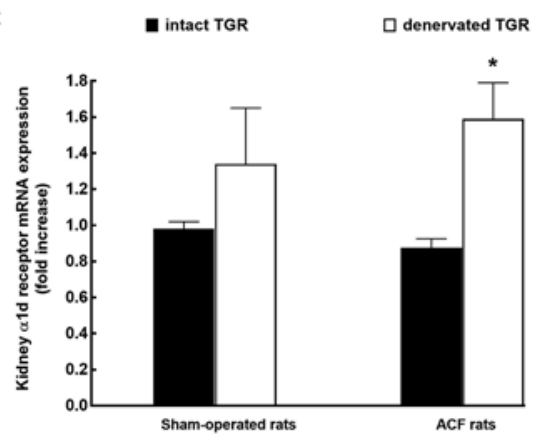

D

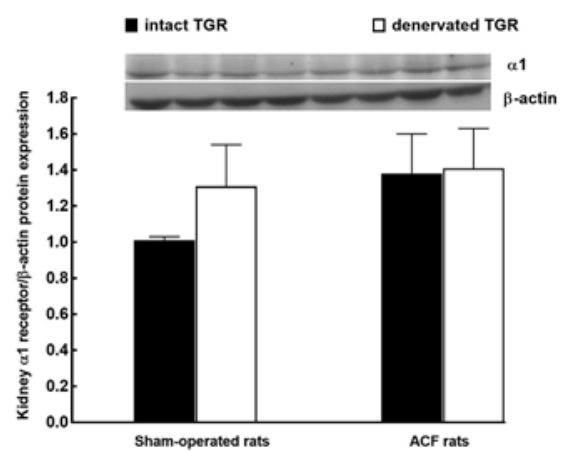

Fig. 9. Kidney alpha $1(\alpha)$ type a, type b, and type d receptor mRNA (A-C) and whole kidney al protein (D) expression in intact, that is, nondenervated (solid bars), and denervated (open bars) TGR that were either with ACF (right-hand side) or sham-operated (left). Representative blots are shown above panel D. ${ }^{*} p<0.05$ versus intact TGR. All the values shown are means \pm SEM. mRNA, messenger ribonucleic acid; TGR, transgenic rats; ACF, aortocaval fistula.

ture studies would be necessary to fully resolve this question, which is far beyond the scope of the present study.

The observed beneficial effects of RDN might simply be related to the removal of deleterious influence of increased renal sympathetic nerve activity (RSNA). As indicated by renal NE spillover in human studies [37, 38, 41] and NE tissue turnover in experimental studies [42], such hyperactivity is associated with increased morbidity. However, we showed here that in intact (nondenervated) ACF TGR, kidney NE concentrations were not higher than in their sham-operated counterparts, suggesting that sympathorenal axis was not activated. This is in disagreement with our own recent studies showing that in ACF animals and particularly ACF TGR $[14,35]$, the renal catecholamine concentration was elevated indicating increased RSNA; the reason for this discrepancy is not clear. It is unlikely for this divergence to be a consequence of methodological inaccuracy in the preparation of tissue samples for the NE assay. The employed method of tissue preparation (i.e., isolation and removal of the adrenal glands and immediate homogenization in precooled methanol) was validated repeatedly and is employed not only by our group but also by many other groups studying the role of RSNA in various physiological and pathophysiological states $[15-22,41]$. On the other hand, our present findings show that employed RDN procedure was fully effective, because kidney NE concentration was reduced by $>90 \%$, indicating virtual abolishment of RSNA. Renal NE concentration is considered a golden standard as a neurochemical marker for the evaluation of RDN effectiveness [28-30]. Even though we found no dramatic RSNA increase (based on kidney NE concentrations), in view of the convincing evidence on sustained sympathoexcitation leading to structural, functional, and neurohormonal dysfunction of multiple organs and systems in CHF [15], one could assume that the removal of such sustained influence of SNS can result in multiple beneficial effects and slow down progression of $\mathrm{CHF}$ in 
ACF TGR. Therefore, some potential mechanisms of such action should be discussed.

First, the beneficial actions might be related to the hyperactivity of the RAS, because its inappropriate compensatory activation is an important determinant of $\mathrm{CHF}$ progression $[7,9,25,26,43]$. In agreement with our recent findings [14], we found again that already at the initial stage of CHF, ACF TGR display marked intrarenal activation of both vasoconstrictor/sodium retaining and vasodilatory/natriuretic axis of the RAS (based on kidney ANG II and ANG 1-7 concentrations, respectively); this again supports the notion that CHF is not a purely hemodynamic disorder $[7,25,26]$. However, since RDN did not alter renal concentrations of ANG II or ANG 1-7, the beneficial effects cannot be simply ascribed to the suppression of the former or augmentation of the latter axis of the RAS in ACF TGR. These findings diverge from the recent studies using the MI-induced model of CHF which showed that beneficial cardioprotective actions of RDN were mediated either by direct inhibition of the vasoconstrictor axis of the RAS [18] or indirectly, by increasing the availability of natriuretic peptides via reduction of renal neprilysin activity [17]. Even though we cannot provide a satisfactory explanation for these discrepancies, the data support the hypothesis on the critical role of the kidney in the progression of CHF. Also supported is the notion that exploration of new therapeutic measures should be performed in a variety of models; as apparent from comparison of our present and earlier studies of the effects of RDN in CHF, some therapeutic measure can prove effective in disorders with different underlying mechanisms.

Second, our hypothesis was that potential beneficial effects of RDN on the course of CHF in ACF TGR are dominantly mediated by improvement of renal function. We showed previously that RBF is decreased at the very early stage of compensation phase of ACF-induced CHF, and persistent renal dysfunction rather than progressing cardiac remodeling was responsible for the reduction in long-term survival rate $[12,13,31,44]$. In addition, our recent study has suggested that altered renal vascular responsiveness, particularly exaggerated renal vascular responsiveness, to ANG II might play an important role in the development of renal dysfunction and can accelerate the decompensation of CHF in ACF TGR [14]. Nevertheless, it is not clear why our hypothesis of the renal origin of the beneficial effect of RDN has not been confirmed. As in our recent study, we found that already in compensated CHF (100\% survival), intact ACF TGR showed augmented RBF responses to intrarenal ANG II, without
MAP alteration. Intrarenal NE caused similar decreases in RBF, whereas Ach, an endothelium-dependent vasodilator, elicited greater RBF increases in intact (nondenervated) ACF TGR than in intact sham-operated (without ACF) TGR. These findings indicate that ACF TGR exhibit selectively enhanced renal vascular responsiveness to ANG II without augmenting the response to NE or impairing the vasodilator response to Ach. Given that intact ACF TGR exhibit elevated intrarenal ANG II concentrations, that selective intrarenal $\mathrm{AT}_{1}$ receptor blockade elicits higher increases in RBF, and also that renal vascular responsiveness to ANG II is higher than in intact sham-operated TGR, a strong support is provided for the notion of high ANG II dependency of renal function in ACF TGR. Since RDN did not alter RBF responses to intrarenal $\mathrm{AT}_{1}$ receptor blockade, it appears that the beneficial effects of RDN in ACF TGR on the survival are not directly mediated by alterations of intrarenal RAS.

On the other side, since intact ACF TGR did not show higher intrarenal NE or greater renal vascular responsiveness to NE (compared to intact sham-operated TGR), it is unlikely that inappropriately increased sympathorenal axis activity plays a direct major role in the pathophysiology of renal dysfunction and progression of CHF in this model. It is known that under physiological conditions, $\mathrm{RBF}$ and GFR do not differ between the innervated and denervated kidney, and a several-fold increase in RSNA is needed to cause renal vasoconstriction sufficient to reduce $\operatorname{RBF}[16,19]$. Since we showed that RDN did not increase basal RBF in the rats with ACF (even though it was lower than in sham-operated TGR), most probably RSNA was not dramatically increased in ACF TGR. In this context, important is also our finding that RDN significantly decreased BP in sham-operated TGR but not in ACF TGR. This suggests that in TGR, hypertension is associated with increased RSNA, an important finding which contradicts the conclusion from the studies using chronic ANG II infusion $[16,19,45]$ that ANG II-dependent hypertension is accompanied by low RSNA and that RDN would not reduce $\mathrm{BP}$ in this model. The present findings indicate that this paradigm should be reconsidered. However, even more important is our finding that $\mathrm{RDN}$ does not decrease $\mathrm{BP}$ in ACF TGR, in agreement with our opinion that RSNA is not considerably increased in ACF TGR.

Of interest is also our finding that $\mathrm{RDN}$ increased renal vascular responsiveness to both doses of $\mathrm{NE}$ and to the higher dose of ANG II in sham-operated TGR as well as ACF TGR. Such postdenervation supersensitivity has been known for decades [46]; it results from the loss of presynaptic neuronal uptake sites for NE. While it was 
initially thought that the supersensitivity to the circulating NE could offset the beneficial effects of RDN $[29,30]$, it was later demonstrated that it is unlikely to be a confounding factor in long-term studies employing RDN $[19,47]$. However, one study [48] employing the radioligand binding technique demonstrated that RDN slightly but significantly increased $\alpha 1$ adrenoreceptors in the chronically denervated kidney. It is unlikely that postRDN supersensitivity, even if combined with increased a1 adrenoreceptors present in the kidney, would have deleterious long-term effects on renal function under physiological conditions (i.e., with low NE concentrations) $[19,47]$. However, under pathophysiological conditions associated with chronically increased NE concentrations and decreased BP, the renal vascular supersensitivity combined with the upregulation of al adrenoreceptors could in the long term significantly alter renal function after RDN. It is worth emphasizing that $\mathrm{CHF}$ is a pathophysiological state in which this would be of particular importance. This notion is further supported by our findings that RDN resulted also in increased renal vascular responsiveness to the higher dose of ANG II and that CHF is accompanied by increased circulating and intrarenal ANG II concentrations. Therefore, we performed additional experiments in which we analyzed renal ANG II and adrenergic receptors using a complex approach comprising the analysis of mRNA and protein expression as well as radioligand binding studies. The results obtained suggest that there were no significant differences in ANG II and adrenergic receptor expressions in the kidney cortex between intact (nondenervated) sham-operated (without ACF) TGR and intact ACF TGR, and $\mathrm{RDN}$ did not alter the receptor expressions in any of experimental groups. Such sound conclusion is possible to be made only because we employed comprehensive analysis (i.e., mRNA and protein expression together with binding studies). It is well known that regulation and function of ANG II and adrenergic receptors in the kidneys is an extremely complex issue $[49,50]$; therefore, the fragmentary analysis (e.g., only mRNA expression) could lead to misleading information regarding long-term actions of RDN on the renal function.

Our present findings support the notion formulated by Giebisch [51] that current nephrology research should encompass interdisciplinary approach, including not only cellular and molecular aspects of renal function but also their physiological relevance to the whole organ and organism function. Nevertheless, the very existence of the supersensitivity to $\mathrm{NE}$ is another indication that the RDN procedure was fully effective.

Renal Denervation in Heart Failure Rats
Of interest are also our findings regarding MAP and RBF responses to systemic (intravenous) administration of ANG II. We found that intact ACF TGR exhibited both attenuated total peripheral vascular responsiveness to ANG II (as seen from the changes in MAP) and maintained renal vascular responsiveness to ANG II (as seen from the changes in RBF) compared with intact shamoperated TGR, and RDN did not modify those MAP and $\mathrm{RBF}$ responses. These findings are in direct contrast to the observations showing exaggerated renal vascular responses to ANG II after intrarenal administration. The same discrepancy was found in our recent studies when comparison of vascular responses to ANG II, NE, and Ach were evaluated after intrarenal and systemic administration in ACF rats $[14,35]$, which again confirms the caveat that for studies evaluating renal vascular responsiveness, the route of administration of vasoactive agents is of critical importance $[52,53]$. Presumably, MAP changes after intravenous administration initiate some indirect effects, such as activation of SNS followed by its effects on peripheral and RVR [19]. It is noteworthy that initial studies in patients and animals with CHF evaluated renal vascular responses to systemic administration of vasoactive agents, which could result in misleading information regarding the role altered renal vascular responsiveness in the development of renal dysfunction in $\mathrm{CHF}$ [12, 54-56].

The third important set of findings to be considered here is the simple organ morphometric data. Earlier studies correlating the organ morphometry and cardiac function (evaluated by echocardiography or by direct hemodynamic pressure-volume analyses) have shown that the organ weights are a reliable predictor of the onset of cardiac decompensation in the ACF-induced model of CHF $[13,57,58]$. Our present findings indicate that as soon as 3 weeks after ACF creation, TGR animals show prominent bilateral cardiac hypertrophy with pronounced lung congestion, however, without an increase in liver weight; all this suggests the development of LV failure. However, the most important finding from the organ morphometric data is that RDN markedly attenuates bilateral cardiac hypertrophy and lung congestion in ACF TGR without altering MAP. Thus, these favorable actions cannot be simply ascribed to the reduced afterload. This opinion is supported by our finding that reduction in MAP after RDN in sham-operated TGR (without ACF) did not decrease LVW, which suggests that the duration and magnitude of this decrease in afterload were not sufficient to elicit significant attenuation in cardiac hypertrophy. $\mathrm{Nev}-$ ertheless, it is possible that even though in ACF TGR 
RDN did not cause significant MAP decrease compared with intact ACF TGR (a decreasing tendency did not reach statistical significance level; $110 \pm 2$ vs. $116 \pm 2 \mathrm{~mm}$ $\mathrm{Hg}, p>0.05$ ), in the long term, it could still result in a significant MAP reduction. It is plausible that even slight reduction in the afterload to the LV in ACF TGR, in contrast to that in sham-operated TGR, could elicit significant reduction in LV hypertrophy. To conclusively resolve this issue, long-term studies are needed involving radiotelemetric BP measurements in conscious animals. However, it was recently pointed out that altered sympathetic outflow to the kidneys after $\mathrm{RDN}$ (the consequence of severing efferent fibers) is important, but represents only a part of the more extensive role of renal nerves in the regulation of renal and cardiovascular function [19]. Since RDN also causes ablation of renal afferent nerves, vasodilatation of nonrenal vascular beds due to interruption of the renal afferent signaling pathway might also be an important component of the beneficial actions of RDN on cardiac hypertrophy and lung congestion.

Another finding of special interest is that in ACF TGR, the degree of RV hypertrophy was markedly higher than LV hypertrophy. More than 20 years ago, Gerdes et al. [59] demonstrated that creation of ACF resulted (within 4 weeks) in more pronounced RV cardiac hypertrophy which was accompanied by elevation in RVSP. Subsequent closure of ACF resulted in normalization of cardiac weights and RVSP, bringing them to values observed in sham-operated animals. Ever since the abovementioned seminal study, it was believed that relatively higher mass of RV compared with LV in the ACF model of CHF is not only the consequence of the volume overload, but also an increased pressure load.

However, this largely accepted notion disregards the contrary evidence from several studies. Some reports indicate that more pronounced RV hypertrophy in the volume-overload models occurred also when RVSP and mean pulmonary arterial pressure (a surrogate for the RV afterload) were quite similar in the sham-operated and ACF groups [60, 61].

In attempt to resolve these contradictory findings and uncertainty regarding the possible role of increased RV afterload in the development of more pronounced RV cardiac hypertrophy, we performed an additional series of experiments evaluating the RVSP at the onset of the decompensated phase of CHF in untreated ACF TGR, that is, at the critical stage when the rats begin to die. We found that untreated ACF TGR exhibit significantly elevated RVSP, which indicates that RV, at least at this phase and in this particular model of ACF-induced CHF, is ex- posed not only to volume overload but also to the concomitant pressure load. Importantly, we found that RDN did not change RVSP in sham-operated animals, but significantly decreased it in ACF TGR, suggesting that the more evident reduction in RV than in $\mathrm{LV}$ after $\mathrm{RDN}$ could be ascribed to the reduction of RV afterload. This notion is supported by a recent study by Bos et al. [62] who provided evidence, using 2 well-established models of pulmonary hypertension, that RDN delayed the disease progression and reduced pulmonary vascular resistance and RV afterload.

Despite the obvious limitation of our present study (mean arterial pulmonary pressure, cardiac output, and consequently pulmonary vascular resistance were not directly measured but calculated), our data suggest that besides the favorable actions of RDN on the LV hypertrophy (not simply mediated by reduction in the afterload), RDN also exhibited advantageous effects mediated, in case of RV, by the reduction in the pressure load. Unfortunately, the current data do not allow us to determine the relative contribution of these 2 different modes of action of RDN on cardiac hypertrophy in ACF TGR or specify the principal mechanism(s) responsible for these beneficial effects. It is apparent that future studies are needed to address this issue. Whatever the exact underlying mechanism(s), our current data indicate that the observed remarkable actions on cardiac hypertrophy and, in particular, lung congestion might be responsible for the improvement of long-term survival in ACF TGR after $\mathrm{RDN}$.

\section{Limitations of the Study}

Apart from the above-discussed reservations, 3 additional limitations of the present study should be considered. First, our data refer only to the effects of RDN on the course of ACF-induced CHF in male TGR. There are obvious sex-related differences in the course of CHF between men and women, regarding the epidemiology, pathophysiology, and responses to new therapeutic measures [63]. Our recent study showed that TGR exhibit remarkable sex-related differences in CHF-related mortality and in response to the pharmacological treatment [64]. Evidently, future studies are necessary to address the role of sex-linked differences in response to $\mathrm{RDN}$ in this model of CHF.

Second, in our experimental arrangement, RDN was performed in the compensated phase CHF, when the rats do not yet exhibit important endothelial dysfunction and 
GFR is still maintained. On the other hand, the patients enrolled to the RDN procedure typically exhibit many comorbidities and their renal dysfunction is in more advanced phase $[4,6,16]$.

Third, our method of combined surgical and chemical denervation is known for its highest effectiveness and completely abolishes the RSNA, whereas the RDN employed in the clinical medicine (radiofrequency ablation method) is of necessity only partly effective. The aforementioned limitations should be considered before prospective implementation of RDN to the clinical practice. However, we are convinced that our present study provides an experimental basis for the application of RDN in the treatment of CHF.

\section{Conclusion}

Our results show that RDN significantly attenuates CHF-dependent mortality in ACF TGR; however, this beneficial effect is not associated with improvement of reduced renal hemodynamics or attenuation of exaggerated renal vascular responsiveness to ANG II. Nor did RDN alter intrarenal activity of the RAS in ACF TGR. Nevertheless, RDN markedly attenuated the progression of cardiac hypertrophy and lung congestion at the onset of the phase of CHF decompensation. In general, these findings support the notion that RDN could be a novel therapeutic measure for the treatment of CHF, particularly in the individuals that were hypertensive before the onset of CHF.

\section{Statement of Ethics}

The studies were performed in accordance with the guidelines and practices established by the Animal Care and Use Committee of the Institute for Clinical and Experimental Medicine, Prague, which accord with the national law and the EU policy and were approved by the Ministry of Health of the Czech Republic (project decision 14553/2019-4/OZV).

\section{Conflict of Interest Statement}

The authors have no conflicts of interest to declare.

\section{Funding Sources}

This study was supported by the Ministry of Health of the Czech Republic, Grant No. NV-18-02-00053 (awarded to L.Č.). All rights reserved.

\section{Author Contributions}

Z.H., V.M., E.K-J., J.S., F.K., and L.Č. primarily conceived and designed the study, analyzed and interpreted the data, and wrote the manuscript. Z.H., P.S., and Z.V. performed all surgical procedures and in vivo experiments in this study. S.K. and Z.Hu. performed all biochemical analyses. Z.H. and F.K. performed invasive hemodynamic assessment. O.G., L.H., Š.J., and J.N. performed the assessment of the kidney gene expression, protein expression, and binding studies. P.K. performed histological analysis. All authors were involved in the final analyses and interpretation of the data, contributed to the intellectual content and editing of the manuscript, and approved its final version.

\section{References}

1 Bulluck H, Yellon DM, Hausenloy DJ. Reducing myocardial infarct size: challenges and future opportunities. Heart. 2016;102(5):341-8.

2 Ponikowski P, Voors AA, Anker SD, Bueno H, Cleland JG, Coats AJ, et al. 2016 ESC Guidelines for the diagnosis and treatment of acute and chronic heart failure: the Task Force for the diagnosis and treatment of acute and chronic heart failure of the European Society of Cardiology (ESC). Developed with the special contribution of the Heart Failure Association (HFA) of the ESC. Eur Heart J. 2016; 37:2129-200.

3 Benjamin EJ, Blaha MJ, Chiuve SE, Cushman M, Das SR, Deo R, et al. Heart disease and stroke statistics-2017 update: a report from the American Heart Association. Circulation. 2017;135(10):e146-603.
4 Normand C, Kaye DM, Povsic TJ, Dickstein K. Beyond pharmacological treatment: an insight into therapies that target specific aspects of heart failure pathophysiology. Lancet. 2019;393(10175):1045-55.

5 Beldhuis IE, Streng KW, Ter Maaten JM, Voors AA, van der Meer P, Rossignol P, et al. Renin-angiotensin system inhibition, worsening renal function, and outcome in heart failure patients with reduced and preserved ejection fraction: a meta-analysis of published study data. Circ Heart Fail. 2017;10(2): e003588.

6 Rangawwami J, Bhalla V, Blair JEA, Chang TI, Costa S, Lentine KL, et al. American Heart Association Council on the Kidney in cardiovascular disease and council on clinical cardiology. Circulation. 2019;139:e840-78.
7 Mullens W, Verbrugge FH, Nijst P, Tang WHW. Renal sodium avidity in heart failure: from pathophysiology to treatment strategies. Eur Heart J. 2017;38(24):1872-82.

8 Packer M, Lee WH, Kessler PD. Preservation of glomerular filtration rate in human heart failure by activation of the renin-angiotensin system. Circulation. 1986;74(4):766-74.

9 Carlstrom M, Wilcox CS, Arendshorst WJ. Renal autoregulation in health and disease. Physiol Rev. 2015;95:405-511.

10 Barger AC, Muldowney FP, Liebowitz MR. Role of the kidney in the pathogenesis of congestive heart failure. Circulation. 1959;20(2): 273-85.

11 Stanton RC, Brenner BM. Role of the kidney in congestive heart failure. Acta Med Scand Suppl. 1986;707:21-5. 
12 Abassi Z, Goltsman I, Karram T, Winaver J, Hoffman A. Aortocaval fistula in rat: a unique model of volume-overload congestive heart failure and cardiac hypertrophy. J Biomed Biotechnol. 2011;2011:729497.

13 Červenka L, Melenovský V, Husková Z Škaroupková P, Nishiyama A, Sadowski J. Inhibition of soluble epoxide hydrolase counteracts the development of renal dysfunction and progression of congestive heart failure in Ren-2 transgenic hypertensive rats with aorto-caval fistula. Clin Exp Pharmacol Physiol. 2015;42(7):795-807.

14 Vacková Š, Kikerlová S, Melenovský V, Kolář F, Imig JD, Kompanowska-Jezierska E, et al. Altered renal vascular responsiveness to vasoactive agents in rats with angiotensin II-dependent hypertension and congestive heart failure. Kidney Blood Press Res. 2019;44(4): 792-809.

15 Antoine S, Vaidya G, Imam H, Villarreal D. Pathophysiologic mechanisms in heart failure: role of the sympathetic nervous system. Am J Med Sci. 2017;353(1):27-30.

16 Lohmeier TE, Hall JE. Device-based neuromodulation for resistant hypertension therapy. Too early for prime time? Circ Res. 2019; 124:1071-93.

17 Polhemus DJ, Trivedi RK, Gao J, Li Z, Scarborough AL, Goodchild TT, et al. Renal sympathetic denervation protects the failing heart via inhibition of neprilysin activity in the kidney. J Am Coll Cardiol. 2017;70(17):2139-53.

18 Sharp TE, Polhemus DJ, Li Z, Spaletra P, Jenkins JS, Reilly JP, et al. Renal denervation prevents heart failure progression via inhibition of the renin-angiotensin system. J Am Coll Cardiol. 2018;72(21):2609-21.

19 Osborn JW, Foss JD. Renal nerves and longterm control of arterial pressure. Compr Physiol. 2017;7(2):263-320.

20 Zheng XX, Li XY, Lyu YN, He YY, Wan WG, Zhu HL, et al. Possible mechanism by which renal sympathetic denervation improves left ventricular remodelling after myocardial infarction. Exp Physiol. 2016;101(2):260-71.

21 Pinkham MI, Loftus MT, Amirapu S, Guild SJ, Quill G, Woodward WR, et al. Renal denervation in male rats with heart failure improves ventricular sympathetic nerve innervation and function. Am J Physiol Regul Integr Comp Physiol. 2017;312(3):R368-79.

22 Nasi-Er BG, Lou X, Zhang Y, Sun H, Zhou X, $\mathrm{Li} Y$, et al. Renal sympathetic denervation improves outcomes in a canine myocardial infarction model. Med Sci Monit. 2019;25: 3887-93.

23 Houser SR, Margulies KB, Murphy AM, Spinale FG, Francis GS, Prabhu SD, et al. Animal models of heart failure: a scientific statement from the American Heart Association. Circ Res. 2012;111(1):131-50.

24 Husková Z, Kramer HJ, Vanourková Z, Cervenka $L$. Effects of changes in sodium balance on plasma and kidney angiotensin II levels in anesthetized and conscious Ren-2 transgenic rats. J Hypertens. 2006;24(3):517-27.
25 Dube P, Weber KT. Congestive heart failure: pathophysiologic consequences of neurohormonal activation and the potential for recovery: part I. Am J Med Sci. 2011;342(5):348-51.

26 Packer M. The neurohormonal hypothesis: a theory to explain the mechanism of disease progression in heart failure. J Am Coll Cardiol. 1992;20(1):248-54.

27 Cohen-Segev R, Francis B, Abu-Saleh N, Awad H, Lazarovich A, Kabala A, et al. Cardiac and renal distribution of ACE and ACE2 in rats with heart failure. Acta Histochem. 2014;116(8):1342-9.

28 Bello-Reuss E, Colindres RE, Pastoriza-Muñoz E, Mueller RA, Gottschalk CW. Effects of acute unilateral renal denervation in the rat. J Clin Invest. 1975;56(1):208-17.

29 Kline RL, Mercer PF. Functional reinnervation and development of supersensitivity to $\mathrm{NE}$ after renal denervation in rats. Am J Physiol. 1980;238(5):R353-8.

30 Krayacich J, Kline RL, Mercer PF. Supersensitivity to NE alters renal function of chronically denervated rat kidneys. Am J Physiol. 1987;252 (5 Pt 2):F856-64.

31 Kala P, Sedláková L, Škaroupková P, Kopkan L, Vaňourková Z, Táborský M, et al. Effect of angiotensin-converting enzyme blockade, alone or combined with blockade of soluble epoxide hydrolase, on the course of congestive heart failure and occurrence of renal dysfunction in Ren-2 transgenic hypertensive rats with aorto-caval fistula. Physiol Res. 2018;67(3):401-15.

32 Husková Z, Kopkan L, Červenková L, Doleželová Š, Vaňourková Z, Škaroupková P, et al. Intrarenal alterations of the angiotensinconverting enzyme type 2/angiotensin 1-7 complex of the renin-angiotensin system do not alter the course of malignant hypertension in Cypla1-Ren-2 transgenic rats. Clin Exp Pharmacol Physiol. 2016;43(4):438-49.

33 Cohen J. Some issue in power analysis. In: Cohen J, editor. Statistical power analysis for the behavioral sciences. 2nd ed. New York: Routledege; 2013. p. 531-42.

34 Honetschlägerová Z, Husková Z, Vaňourková Z, Sporková A, Kramer HJ, Hwang SH, et al. Renal mechanisms contributing to the antihypertensive action of soluble epoxide hydrolase inhibition in Ren-2 transgenic rats with inducible hypertension. J Physiol. 2011; 589(Pt 1):207-19.

35 Kratky V, Kopkan L, Kikerlova S, Huskova Z, Taborsky M, Sadowski J, et al. The role of renal vascular reactivity in the development of renal dysfunction in compensated and decompensated congestive heart failure. Kidney Blood Press Res. 2018;43(6):1730-41.

36 Jíchová Š, Doleželová Š, Kopkan L, Kompanowska-Jezierska E, Sadowski J, Červenka L. Fenofibrate attenuates malignant hypertension by suppression of the renin-angiotensin system: a study in Cyp1a1-Ren-2 transgenic rats. Am J Med Sci. 2016;352(6):618-30.
37 Petersson M, Friberg P, Eisenhofer G, Lambert G, Rundqvist B. Long-term outcome in relation to renal sympathetic activity in patients with chronic heart failure. Eur Heart J. 2005;26(9):906-13.

38 Jose P, Skali H, Anavekar N, Tomson C Krumholz HM, Rouleau JL, et al. Increase in creatinine and cardiovascular risk in patients with systolic dysfunction after myocardial infarction. J Am Soc Nephrol. 2006;17(10): 2886-91.

39 Hillege HL, Girbes AR, de Kam PJ, Boomsma F, de Zeeuw D, Charlesworth A, et al. Renal function, neurohormonal activation, and survival in patients with chronic heart failure. Circulation. 2000;102(2):203-10.

40 Arendshorst WJ, Navar LG. Renal circulation and glomerular hemodynamics. In: Schrier RW, Gottschalk CW, editors. Diseases of the kidney. 5th ed. 1993. p. 65-118.

41 Ramchandra R, Barrett CJ. Regulation of the renal sympathetic nerves in heart failure. Front Physiol. 2015;6:238.

42 Patel KP, Zhang K, Carmines PK. Norepinephrine turnover in peripheral tissues of rats with heart failure. Am J Physiol Regul Integr Comp Physiol. 2000;278(3):R556-62.

43 Jonsson S, Agic MB, Narfstrom F, Melville JM, Hutstrom M. Renal neurohormonal regulation in heart failure decompensation. Am J Physiol. 2014;307:R493-497.

44 Vacková Š, Kopkan L, Kikerlová S, Husková Z, Sadowski J, Kompanowska-Jezierska E, et al. Pharmacological blockade of soluble epoxide hydrolase attenuates the progression of congestive heart failure combined with chronic kidney disease: insights from studies with Fawn-hooded hypertensive rats. Front Pharmacol. 2019;18:18.

45 Foss JD, Fiege J, Shimizu Y, Collister JP, Mayerhofer T, Wood L, et al. Role of afferent and efferent renal nerves in the development of AngII-salt hypertension in rats. Physiol Rep. 2018;6(3).

46 Trendelenburg U. Mechanisms of supersensitivity and subsensitivity to sympathomimetic amines. Pharmacol Rev. 1966;18(1):629-40.

47 Lohmeier TE, Reinhart GA, Mizelle HL, Han M, Dean MM. Renal denervation supersensitivity revisited. Am J Physiol. 1998;275(4 Pt 2):R1239-46

48 Woodcock EA, Morris MJ, McLeod JK, Johnston CI. Specific increase in renal alpha 1-adrenergic receptors following unilateral renal denervation. J Recept Res. 1985;5(2-3):13346.

49 Insel PA, Snavely MD. Catecholamines and the kidney: receptors and renal function. Annu Rev Physiol. 1981;43:625-36.

50 Forrester SJ, Booz GW, Sigmund CD, Coffman TM, Kawai T, Rizzo V, et al. Angiotensin II signal transduction: an updated on mechanisms of physiology and pathophysiology. Physiol Rev. 2018;98:1627-738.

51 Giebisch GH. A long affair with renal tubules. Annu Rev Physiol. 2011;73:1-28. 
52 Kopkan L, Kramer HJ, Husková Z, Vanourková Z, Skaroupková $P$, Thurmová $\mathrm{M}$, et al. The role of intrarenal angiotensin II in the development of hypertension in Ren-2 transgenic rats. J Hypertens. 2005;23(8): 1531-9.

53 Jacinto SM, Mullins JJ, Mitchell KD. Enhanced renal vascular responsiveness to angiotensin II in hypertensive Ren-2 transgenic rats. Am J Physiol. 1999;276(2 Pt 2):F315-22.

54 Duggan DJ, Tabrizchi R. Angiotensin II control of regional haemodynamics in rats with aortocaval fistula. Exp Physiol. 2016;101: 1192-205.

55 Abassi ZA, Gurbanov K, Mulroney SE, Potlog C, Opgenorth TJ, Hoffman A, et al. Impaired nitric oxide-mediated renal vasodilatation in rats with experimental heart failure: role of angiotensin II. Circulation. 1997;96:3655-64.

56 Kubo SH, Rector TS, Bank AJ, Williams RE, Heifetz SM. Endothelium-dependent vasodilation is attenuated in patients with heart failure. Circulation. 1991;84(4):1589-96.
57 Oliver-Dussault C, Ascah A, Marcil M, Matas J, Picard S, Pibarot P, et al. Early predictors of cardiac decompensation in experimental volume overload. Mol Cell Biochem. 2010; 338(1-2):271-82.

58 Hutchinson KR, Guggilam A, Cismowski MJ, Galantowicz ML, West TA, Stewart JA, et al. Temporal pattern of left ventricular structur$\mathrm{al}$ and functional remodeling following reversal of volume overload heart failure. J Appl Physiol. 2011;111(6):1778-88.

59 Gerdes AM, Clark LC, Capasso JM. Regression of cardiac hypertrophy after closing an aortocaval fistula in rats. Am J Physiol. 1995; 268(6 Pt 2):H2345-51.

60 Urabe Y, Hamada Y, Spinale FG, Carabello BA, Kent RL, Cooper G, et al. Cardiocyte contractile performance in experimental biventricular volume-overload hypertrophy. Am J Physiol. 1993;264(5 Pt 2):H1615-23.
61 Karamlou T, Giraud GD, McKeogh D, Jonker SS, Shen I, Ungerleider RM, et al. Right ventricular remodeling in response to volume overload in fetal sheep. Am J Physiol Heart Circ Physiol. 2019;316(5):H985-91.

62 da Silva Gocalves Bos D, Happé C, Schalij I, Pijacka W, Paton JFF, Gignabert C, et al. Renal denervation reduces pulmonary vascular remodeling and right ventricular diastolic stiffness in experimental pulmonary hypertension. JACC Basic Transl Sci. 2017;2:22-35.

63 Lam CSP, Arnott C, Beale AL, Chandramouli C, Hilfiker-Kleiner D, Kaye DM, et al. Sex differences in heart failure. Eur Heart J. 2019; 40(47):3859-68c

64 Kala P, Červenka L, Škaroupková P, Táborský M, Kompanowska-Jezierska E, Sadowski J. Sex-linked differences in the mortality in Ren-2 transgenic hypertensive rats with aorto-caval fistula: effects of treatment with angiotensin converting enzyme alone and combined with inhibitor of soluble epoxide hydrolase. Physiol Res. 2019;68(4):589-601. 